\title{
WILEY-VCH
}

DOI: 10.1002/ ((please add manuscript number))

Article type: Full Paper

\section{A Targeted Functional Design for Highly Efficient and Stable Cathodes for Rechargeable Li-Ion Batteries}

Guanjie He ${ }^{a, c}$, Xiaoyu Han ${ }^{a}$, Rujia Zou ${ }^{b, *}$, Tingting Zhao ${ }^{a}$, Zhe Weng ${ }^{c}$, SocMan Ho-Kimura ${ }^{a}$, Yao Lu ${ }^{a}$, Hailiang Wang $^{c}$, Zheng Xiao Guo and Ivan P. Parkin ${ }^{a}$ *

Guanjie He, Dr. Xiaoyu Han, Tingting Zhao, Dr. SocMan Ho-Kimura, Yao Lu, Prof. Zheng Xiao Guo, Prof. Ivan P. Parkin

${ }^{a}$ Christopher Ingold Laboratory, Department of Chemistry, University College London, 20 Gordon Street, London WC1H OAJ, U.K.,

E-mail:i.p.parkin@ucl.ac.uk

Prof. Rujia Zou

${ }^{b}$ State Key Laboratory for Modification of Chemical Fibers and Polymer Materials, College of Materials Science and Engineering, Donghua University, Shanghai 201620, China, Email:rjzou@dhu.edu.cn

Guanjie He, Dr. Zhe Weng, Prof. Hailiang Wang

${ }^{c}$ Department of Chemistry and Energy Sciences Institute, Yale University, 810 West Campus Drive, West Haven, Connecticut 06516, U.S.A. 


\section{WILEY-VCH}

Rechargeable lithium ion batteries (LIBs) are widely used for energy storage in portable devices, due to their low cost, light weight, high energy density, no memory effect, long life span and low-toxicity to the environment. ${ }^{[1,2]}$ Despite the current success, the increasing demand for better performance stimulates further improvements in LIBs, especially energy density, cycling stability and rate capability with the emergency of a new generation of electronic devices and electric vehicles. However, the energy density of LIBs is restricted by the low capacity of cathode materials. ${ }^{[3,4]}$ Most of the commercial cathode materials, such as $\mathrm{LiCoO}_{2}, \mathrm{LiMn}_{2} \mathrm{O}_{4}$ and $\mathrm{LiFePO}_{4},{ }^{[5]}$ can only allow a theoretical maximum of one $\mathrm{Li}^{+}$ion insertion/extraction per formula unit due to their inherent crystal structure and redox chemistry. Hence, multi-Li ion insertion/extraction cathode materials are highly desirable in order to realize the high capacity and fast charge capability of LIBs.

Vanadium pentoxide $\left(\mathrm{V}_{2} \mathrm{O}_{5}\right)$ is one of the promising candidates for such requirements, due to its high theoretical capacity, low cost and ease of synthesis. Its layered structure can readily undergo insertion/extraction of multiple $\mathrm{Li}$ ions via reversible phase transformations, i.e. structural formula of $\mathrm{Li}_{\mathrm{x}} \mathrm{V}_{2} \mathrm{O}_{5}, \alpha$ phase: $\mathrm{x}<0.1 ; \epsilon$ phase: $0.35<\mathrm{x}<0.7 ; \delta$ phase: $\mathrm{x}=1 ; \gamma$ phase: $1<\mathrm{x}<3$ and $\omega$ phase: $\mathrm{x}=3 .^{[6]}$ When two Li ions per formula unit take part in the intercalation process, the theoretical capacity can reach $294.0 \mathrm{~mA} \mathrm{~h} \mathrm{~g}^{-1}$ within the voltage range of 2.0-4.0 V. However, low Li diffusion efficiency, poor electronic conductivity and poor structural stability drag down the electrochemical performance of $\mathrm{V}_{2} \mathrm{O}_{5} \cdot{ }^{[4,6-8]}$ Two proposed solutions have been made. One is the design of novel $\mathrm{V}_{2} \mathrm{O}_{5}$ structures, such as nanosheets ${ }^{[5,9]}$, microspheres ${ }^{[10]}$ and nanobelts ${ }^{[7]}$. Those structures can enlarge the specific surface area and improve the diffusion efficiency of Li. Recently, ultra-large $\mathrm{V}_{2} \mathrm{O}_{5}$ nanosheets that are exceptionally thin were fabricated by Liang et al. These nanosheets possess a high specific discharge capacity of $141 \mathrm{~mA} \mathrm{~h} \mathrm{~g}^{-1}$ at a current density of $0.1 \mathrm{~A} \mathrm{~g}^{-1}$ with $92.6 \%$ retention after 500 cycles. ${ }^{[11]}$ Another focus is to fabricate $\mathrm{V}_{2} \mathrm{O}_{5}$ based composite materials to 


\section{WILEY-VCH}

improve the electrochemical performance. For example, $\mathrm{V}_{2} \mathrm{O}_{5}$-graphene xerogel $^{[6]}$, $\mathrm{SnO}_{2} / \mathrm{V}_{2} \mathrm{O}_{5}$ composites ${ }^{[12]}$ and $\mathrm{V}_{2} \mathrm{O}_{5} /$ mesoporous carbon composites ${ }^{[13]}$.

Compared with the slurry making process required above, ${ }^{[6-13]}$ direct growth of nanostructures on a current collecting substrate has been shown to avoid complex processing procedures. Previous reports have shown the avoidance of the drawbacks and complicated procedures of mixing active electrode materials with binders and conductive agents to increase the endurance of the fast charge and discharge operations. ${ }^{[14,15]}$ However, there are still some common issues for the reported core-shell composite structures ${ }^{[4,16-19]}: 1$ ) both the core and the shell structures take part in the electrochemical reactions for energy storage simultaneously, which will still introduce instability and unsatisfactory cycling performance of the electrodes due to relatively large volumetric changes or even dissolution of the core structures; and 2) active materials are partially wrapped by inert protective materials, reducing their effectiveness.

With consideration of the above and further guidance from our computational simulations, we developed an integrated approach to design and synthesize a $\mathrm{V}_{2} \mathrm{O}_{5}$ coated $\mathrm{NiCo}_{2} \mathrm{O}_{4}$ nanonetwork structure supported by carbon cloth, 3D NiCo $\mathrm{O}_{4} @ \mathrm{~V}_{2} \mathrm{O}_{5}$ core-shell arrays (CSAs). The $\mathrm{NiCO}_{2} \mathrm{O}_{4}$-nanosheet network is first grown onto the carbon cloth support structure and then the optimised thickness of layered $\mathrm{V}_{2} \mathrm{O}_{5}$-is coated onto the $\mathrm{NiC}_{2} \mathrm{O}_{4}$-network. This approach effectively separates the characteristic roles of high $\mathrm{Li}$ incorporation in $\mathrm{V}_{2} \mathrm{O}_{5}$-and electronic conduction via. $\mathrm{NiCe}_{2} \mathrm{O}_{4}$ and carbon cloth. Meanwhile, the volume change of $\mathrm{V}_{2} \mathrm{O}_{5}$ during lithation/delithation is fully accommodated by the robust $\mathrm{NiCO}_{2} \mathrm{O}_{4}$ nanosheet network, without exerting undue stress on the carbon cloth. The carbon cloth strongly supporting the $\mathrm{NiCo}_{2} \mathrm{O}_{4}$ nanosheet network that acts as a robust framework and provides electron conductive channels for the whole structure, and it remains mechanically and chemically stable over the 


\section{WILEY-VCH}

high voltage range, $2.0-4.0 \mathrm{~V} v s$. $\mathrm{Li}^{+} / \mathrm{Li}$, even after long-term cycles. The $\mathrm{V}_{2} \mathrm{O}_{5}$ coating solely participated in lithiation/delithiation. Such structural design ensures concerted optimization of capacity, conductivity and structural stability, which are the major issues of the cathode of Li ion batteries. The whole structure reached the theoretical predicted capacity and has among the best reported cycling stability of electrodes for LIBs. Furthermore in-situ TEM study and theoretical simulations also provide insights into the robustness of the nanomaterials and the mechanism of the layer effects in these rational structures, which will guide $\mathrm{V}_{2} \mathrm{O}_{5}$ based LIBs studies in the future. This free-standing electrode provides a series of advantages: flexibility; large surface area; easy access of electrolyte; and efficient electron/ion transport capability. Those also show potential applications as cathodes for foldable/flexible Li-battery devices.

The schematic procedure of generating the $\mathrm{NiCO}_{2} \mathrm{O}_{4} @ \mathrm{~V}_{2} \mathrm{O}_{5} \mathrm{CSAs} /$ carbon cloth was illustrated in Figure 1a and elaborated in details in the Experimental section in the supporting information. The flexible conductive carbon cloth, with potential applications for wearable LIB devices, were chosen as the current collector to support the whole electrodes. Firstly, $\mathrm{NiCo}_{2} \mathrm{O}_{4}$ nano-network was synthesized on the chosen substrate by a simple hydrothermal method followed by annealing to enhance the crystallinity, bonding and hence electron conductivity. Those porous network structure provides strong support and binding with the $\mathrm{V}_{2} \mathrm{O}_{5}$ shell. More importantly, $\mathrm{NiCo}_{2} \mathrm{O}_{4}$ nanostructure possesses much better electron conductivity, 5 6 orders of magnitudes higher than that of $\mathrm{V}_{2} \mathrm{O}_{5}{ }^{[20-23]}$. The nano-architectured design also benefits from the open channels of $3 \mathrm{D} \mathrm{NiCo} \mathrm{O}_{4}$ nanostructure which are easy to access by the electrolyte and hence enable efficient ion transfer. Secondly, $\mathrm{V}_{2} \mathrm{O}_{5}$ nanosheets were coated on both sides of the $\mathrm{NiCO}_{2} \mathrm{O}_{4}$ nanosheets arrays by the hydrothermal method and formed a well-connected core-shell network structure. The strong structure and the binding between the structure and the carbon-support partially alleviates the possible stress of volume 


\section{WILEY-VCH}

expansion from the lithiation process. In order to obtain the best electrochemical performances, different concentrations of reaction solution $(0.1 \sim 0.4 \mathrm{~mL})$ were adjusted to identify the appropriate thickness ratio of the core-shell network.

The morphologies of the pure carbon cloth, $\mathrm{NiCo}_{2} \mathrm{O}_{4} /$ carbon cloth and those of $\mathrm{NiCo}_{2} \mathrm{O}_{4} @ \mathrm{~V}_{2} \mathrm{O}_{5} \mathrm{CSAs} /$ carbon cloth were determined by SEM. The pure carbon fibers are interweaved and formed cloth with a surface structure facilitating heterogeneous nucleation of the $\mathrm{NiCo}_{2} \mathrm{O}_{4}$ (Figure S1). After the initial reaction, $\mathrm{NiCo}_{2} \mathrm{O}_{4}$ nanosheets were grown over the individual carbon fibers to form a nano-network with a mesoporous structure (Figure S2). For the growth of $\mathrm{V}_{2} \mathrm{O}_{5}$ shell on the $\mathrm{NiCo}_{2} \mathrm{O}_{4}$ core, when the pre-reaction solution was at $0.1 \mathrm{~mL}$, the morphologies of the nanosheets become rough with small nanoparticles adhered on the surfaces (Figures S3a, 1b). When the concentration of the precursor solution was increased to $0.2 \mathrm{~mL}, \mathrm{~V}_{2} \mathrm{O}_{5}$ nanosheets were observed that were capped on both sides of the $\mathrm{NiCo}_{2} \mathrm{O}_{4}$ sheets forming sandwich structures (Figures S3b, 1c). Further increases of the vanadium oxytriisopropoxide solution to 0.3 and $0.4 \mathrm{~mL}$, the thickness of the $\mathrm{V}_{2} \mathrm{O}_{5}$ nanosheets increased dramatically (Figures S3c, 3d and Figures 1d, 1e). A mass of the nanosheets stack together and even block the porous structures, thus retarding the $\mathrm{Li}^{+}$ion diffusion and electron transfer during electrochemical reactions.

The detailed topography and microstructure of the sandwich-like structures were further analyzed by transmission electron microscopy (TEM). From the low magnification TEM image (Figure 2a), the nanosheets show clearly the mesoporous structure with pore sizes of several hundred nanometers to micrometers. A high magnification TEM image in Figure $2 \mathrm{~b}$ shows more clearly the nanosheet morphology of the structure. Such structures provide high specific open surface areas for easy soaking of the electrolyte, and fast transfer of ions and electrons. The mesoporous structures can be detected on the individual nanosheet. High 


\section{WILEY-VCH}

resolution TEM (HRTEM) image of the interface between $\mathrm{NiCo}_{2} \mathrm{O}_{4}$ and $\mathrm{V}_{2} \mathrm{O}_{5}$ is shown in Figure 2c, where the lattice space of $\sim 0.234 \mathrm{~nm}$ corresponds to the (222) plane of the $\mathrm{NiCo}_{2} \mathrm{O}_{4}$ spinel structure, and the lattice spacing of $\sim 0.265$ and $\sim 0.438 \mathrm{~nm}$ can be indexed to the (310) and (001) planes of the $\mathrm{V}_{2} \mathrm{O}_{5}$ orthorhombic structure, respectively. The heterostructures formed strong coherency across the interface, due to the relatively small lattice mismatch, which ensures the sandwich structure integrity to facilitate large levels of $\mathrm{Li}^{+}$insertion/extraction. The crystallographic phases of the $\mathrm{NiCo}_{2} \mathrm{O}_{4} @ \mathrm{~V}_{2} \mathrm{O}_{5} \mathrm{CSAs} /$ carbon cloth were further characterized by X-ray diffraction (XRD), Figure 2d, where the two main diffraction peaks at $14.1^{\circ}$ and $20.2^{\circ}$ are indexed to the (110) crystal planes of the orthorhombic phase of $\mathrm{V}_{2} \mathrm{O}_{5}$ and (400) crystal plane of the spinal phase $\mathrm{NiCo}_{2} \mathrm{O}_{4}$, respectively. A series of relatively weak and somewhat broad peaks can be indexed to $\mathrm{V}_{2} \mathrm{O}_{5}$ (JCPDS no. 41-1426) and $\mathrm{NiCo}_{2} \mathrm{O}_{4}$ (JCPDS no. 20-0781), respectively. Furthermore, the phase of $\mathrm{V}_{2} \mathrm{O}_{5}$ powder samples was recorded by XRD in Figure S4b, which showed more evident diffraction peaks with smaller width at half maxima intensity that corresponded to the orthorhombic phase of $\mathrm{V}_{2} \mathrm{O}_{5}$. The elemental distribution of the $\mathrm{NiCo}_{2} \mathrm{O}_{4} @ \mathrm{~V}_{2} \mathrm{O}_{5} \mathrm{CSAs}$ was detected by X-ray mapping with a matching TEM image, this revealed that $\mathrm{Ni}, \mathrm{Co}, \mathrm{V}$ and $\mathrm{O}$ are uniformly distributed in the core $(\mathrm{Ni}, \mathrm{Co}, \mathrm{O})$ and the shell $(\mathrm{V}, \mathrm{O})$ regions, which is in accordance with the $\mathrm{X}$-ray photoelectron spectroscopy (XPS) spectra (Figure S5).

The electrochemical properties of the four $\mathrm{NiCo}_{2} \mathrm{O}_{4} @ \mathrm{~V}_{2} \mathrm{O}_{5}$ CSAs as the cathodes for LIBs were evaluated, Figure 3. The cycling performance was investigated under a current density of $0.5 \mathrm{C}$ for 100 cycles as shown in Figure 3a. As expected, sandwich-structural $\mathrm{NiCo}_{2} \mathrm{O}_{4} @ \mathrm{~V}_{2} \mathrm{O}_{5} \mathrm{CSAs}$, sample 1c, shows the best performance with the highest discharge capacity of $\sim 276.4 \mathrm{~mA} \mathrm{~h} \mathrm{~g}^{-1}$, calculated by the total mass of $\mathrm{NiCo}_{2} \mathrm{O}_{4}$ framework and $\mathrm{V}_{2} \mathrm{O}_{5}$ active material, compared with other samples (discharge capacity of $\sim 238.9 \mathrm{~mA} \mathrm{~h} \mathrm{~g}^{-1}, \sim 197.3$ $\mathrm{mA} \mathrm{h} \mathrm{g}^{-1}$ and $\sim 166.8 \mathrm{~mA} \mathrm{~h} \mathrm{~g}^{-1}$ for sample $1 \mathrm{~b}, 1 \mathrm{~d}$ and $1 \mathrm{e}$, respectively). The results indicate that 


\section{WILEY-VCH}

the thickness of the $\mathrm{V}_{2} \mathrm{O}_{5}$ nanosheet out-layers affects the specific capacity. The following electrochemical performance was carried out using the sandwich-structural $\mathrm{NiCo}_{2} \mathrm{O}_{4} @ \mathrm{~V}_{2} \mathrm{O}_{5}$ CSAs unless stated otherwise.

The CV curves of the first and second cycles at a scan rate of $0.1 \mathrm{mV} \mathrm{s}^{-1}$ in the voltage window of $2.0-4.0 \mathrm{~V}$ vs. $\mathrm{Li} / \mathrm{Li}^{+}$are shown in Figure $3 \mathrm{~b}$. In the second stable cycle, the first cathodic peak at $3.34 \mathrm{~V}$ can be indexed to phase changes from $\alpha-\mathrm{Li}_{\mathrm{x}} \mathrm{V}_{2} \mathrm{O}_{5}(\mathrm{x}<0.1)$ to $\varepsilon$ $\mathrm{Li}_{0.5} \mathrm{~V}_{2} \mathrm{O}_{5}$. Other two reduction peaks at 3.13 and $2.23 \mathrm{~V}$ can be attributed to the formation of $\delta-\mathrm{LiV}_{2} \mathrm{O}_{5}$ and $\gamma-\mathrm{Li}_{2} \mathrm{~V}_{2} \mathrm{O}_{5}$, respectively. In the $\mathrm{Li}$ de-intercalation process, three anodic peaks observed at 2.52, 3.28 and $3.48 \mathrm{~V}$ correspond to the reverse phase transformations, i.e. from $\gamma-\mathrm{Li}_{2} \mathrm{~V}_{2} \mathrm{O}_{5}, \delta-\mathrm{LiV}_{2} \mathrm{O}_{5}, \varepsilon-\mathrm{Li}_{0.5} \mathrm{~V}_{2} \mathrm{O}_{5}$ to $\alpha-\mathrm{Li}_{\mathrm{x}} \mathrm{V}_{2} \mathrm{O}_{5}(\mathrm{x}<0.1)$, respectively. There are no other peaks from the $\mathrm{CV}$ curves, suggesting only the $\mathrm{V}_{2} \mathrm{O}_{5}$ phase transformations take place in the electrochemical reactions. This also indicates the stability of the network structure during the whole electrochemical process. The reaction steps can be expressed in the following ${ }^{[3]}$ :

$$
\begin{array}{ll}
\mathrm{V}_{2} \mathrm{O}_{5}+0.5 \mathrm{Li}^{+}+0.5 \mathrm{e}^{-} \leftrightarrow \varepsilon-\mathrm{Li}_{0.5} \mathrm{~V}_{2} \mathrm{O}_{5} & \text { Equation (1) } \\
\varepsilon-\mathrm{Li}_{0.5} \mathrm{~V}_{2} \mathrm{O}_{5}+0.5 \mathrm{Li}^{+}+0.5 \mathrm{e}^{-} \leftrightarrow \delta-\mathrm{LiV}_{2} \mathrm{O}_{5} & \text { Equation (2) } \\
\delta-\mathrm{LiV}_{2} \mathrm{O}_{5}+\mathrm{Li}^{+}+\mathrm{e}^{-} \leftrightarrow \gamma-\mathrm{Li}_{2} \mathrm{~V}_{2} \mathrm{O}_{5} & \text { Equation (3) }
\end{array}
$$

Figure $3 \mathrm{c}$ shows the first, second and fifth cycles of the CD profiles for the $\mathrm{NiCo}_{2} \mathrm{O}_{4} @ \mathrm{~V}_{2} \mathrm{O}_{5}$ CSAs at a current density of $0.1 \mathrm{C}$. After the first cycle to form the solid state electrolyte interface layer, the capacity remains stable and then slowly decreases. As shown in the figure, there is no evident flat voltage plateaus in the charge and discharge curves, which corresponds with a relatively low crystallinity of the $\mathrm{V}_{2} \mathrm{O}_{5}$ structure. It is demonstrated that lower crystallinity can lead to less stress on the electrodes during the Li ion insertion/extraction and better cyclic performance. In line with the above $\mathrm{CV}$ results, three distinct voltage stages could be observed at 3.40-3.32, 3.15-3.10 and 2.35-2.23 $\mathrm{V}$ on the discharge curves. Those 


\section{WILEY-VCH}

stages represent the $\mathrm{Li}$ ion intercalation processes. Likewise, three corresponding voltage stages at $2.42-2.55,3.20-3.35$ and $3.42-3.53 \mathrm{~V}$ are related to the $\mathrm{Li}$ ion de-intercalation processes. Both $\mathrm{CV}$ and $\mathrm{CD}$ results confirm the multi-step $\mathrm{Li}$ intercalation process.

Rate capabilities of the $\mathrm{NiCo}_{2} \mathrm{O}_{4} @ \mathrm{~V}_{2} \mathrm{O}_{5}$ CSAs are shown in Figure 3d. A stable discharge capacity of $292.0 \mathrm{~mA} \mathrm{~h} \mathrm{~g}^{-1}$ was delivered at a current density of $0.1 \mathrm{C}$, with increasing current density, the discharge capacity decreases to $256.8,198.4,151.9$ and $128.7 \mathrm{~mA} \mathrm{~h} \mathrm{~g}^{-1}$, respectively at $1.0 \mathrm{C}, 5.0 \mathrm{C}, 10 \mathrm{C}$ and $20 \mathrm{C}$. It is noted that the electrodes show good rate performance with $\sim 45 \%$ retention when the current density is increased by 200 times. This is higher than a large series of reported cathode nanostructures for LIBs (Table S1). The specific discharge capacity of $271.6 \mathrm{mAh} \mathrm{g}^{-1}$ can be maintained when the current density was recovered to $0.1 \mathrm{C}$ after 60 cycles of stepwise current density changes, corresponding to a capacity retention of $\sim 93.0 \%$ of its initial value. These improvements can be attributed to the complete $\mathrm{Li}$ intercalation/de-intercalation reaction of the $\mathrm{V}_{2} \mathrm{O}_{5}$ coating and rapid charge and $\mathrm{Li}^{+}$transfer within the whole heterostructure. The specific discharge capabilities of the $\mathrm{NiCO}_{2} \mathrm{O}_{4}$ nanosheet are shown in Figure S6. These contribute negligible capabilities of 14.6 and $6.9 \mathrm{mAh} \mathrm{g}^{-1}$ at current densities of $0.1 \mathrm{C}$ and $1 \mathrm{C}$, respectively. It can be concluded that the "core" $\mathrm{NiCo}_{2} \mathrm{O}_{4}$ shows no electrochemical reactions with $\mathrm{Li}^{+}$within the voltage range of 2.0-4.0 $\mathrm{V} v s . \mathrm{Li}^{+} / \mathrm{Li}$ and this largely insignificant capacity is from the limited ion absorption on the surface of the nanosheets.

To tackle the persistent challenge of unsatisfied cyclic stability, the $\mathrm{NiCo}_{2} \mathrm{O}_{4} @ \mathrm{~V}_{2} \mathrm{O}_{5} \mathrm{CSAs}$ electrode was evaluated under 500 cycles of a cyclic CD test at a high current density of $10 \mathrm{C}$, Figure 3e. Impressively, except for the first few cycles, the cycling stability was largely maintained with only $0.0126 \%$ capacity loss per cycle within 500 cycles and with a Coulombic efficiency $>99.5 \%$. For comparison, flower-like $\mathrm{V}_{2} \mathrm{O}_{5}$ nanoparticles (SEM in 


\section{WILEY-VCH}

Figure $\mathrm{S} 4 \mathrm{a}$ ) and $\mathrm{V}_{2} \mathrm{O}_{5} /$ carbon clothes were fabricated into coin cells as cathodes for LIBs. After 500 cycles under the same conditions, the capacities retained are $40.7 \%$ and $33.5 \%$ of their initial value, respectively, equivalent to $0.12 \%$ and $0.13 \%$ capacity decay per cycle. Hence, $\mathrm{NiCo}_{2} \mathrm{O}_{4} @ \mathrm{~V}_{2} \mathrm{O}_{5} \mathrm{CSAs} /$ carbon cloth improved the cycling stability by 10 times, compared with the $\mathrm{V}_{2} \mathrm{O}_{5}$ nanoparticles and $\mathrm{V}_{2} \mathrm{O}_{5}$ /carbon cloth synthesized by the same procedure. All these results demonstrate the excellent cyclic stability and reversibility with no side reactions in the $\mathrm{NiCo}_{2} \mathrm{O}_{4} @ \mathrm{~V}_{2} \mathrm{O}_{5}$ SAs/carbon cloth electrodes. Compared with the literatures, the exceptional cycling performance of the $\mathrm{NiCo}_{2} \mathrm{O}_{4} @ \mathrm{~V}_{2} \mathrm{O}_{5} \mathrm{CSAs} /$ carbon cloth electrodes is among the best reported nanostructures for cathodes of LIBs (Table S1). This long lifetime was consistent with the almost unchanging morphology of the morphology after 500 cycles: though the sandwich network became relatively thick, Figure S8a, the porous structures of $\mathrm{NiCo}_{2} \mathrm{O}_{4} @ \mathrm{~V}_{2} \mathrm{O}_{5} \mathrm{CSAs}$ structure remains intact. As for powdery $\mathrm{V}_{2} \mathrm{O}_{5}$ samples, the surface appeared to be rough with the nanoparticles further stacking together, Figure S8b, which reduces the electrolyte accessibility and the electrochemical intercalation processes. The extraordinary performance stability and the morphologies further verify the successful benefit from the rational design and the robustness of the open network structure.

As mentioned before, poor structural stability, inferior electron conductivity and sluggish Li diffusivity are the main issues of the $\mathrm{V}_{2} \mathrm{O}_{5}$ nanosheet cathodes for LIBs. The first issue, i.e. structural instability, mainly originated from the strains induced by the volumetric expansion of the electrochemical active material during the lithiation process. It can lead to fracture, falling off and electrical disconnection with the framework or the current collector, which will shorten the service life of LIBs. In-situ TEM observation was carried out to detect the mechanical properties and morphology evolution of $\mathrm{NiCo}_{2} \mathrm{O}_{4} @ \mathrm{~V}_{2} \mathrm{O}_{5}$ CSAs during Li intercalation and de-intercalation from the $\mathrm{V}_{2} \mathrm{O}_{5}$ layers, using a dual-probe biasing TEM holder, as shown in Figure 4a. $\mathrm{NiCo}_{2} \mathrm{O}_{4} @ \mathrm{~V}_{2} \mathrm{O}_{5} \mathrm{CSAs}$ were assembled on a Pt wire probe, the 


\section{WILEY-VCH}

opposite was an $\mathrm{Au}$ wire probe decorated with a small piece of $\mathrm{Li} / \mathrm{Li}_{2} \mathrm{O}$. By controlling a piezoelectric motor on the TEM holder, the $\mathrm{NiCo}_{2} \mathrm{O}_{4} @ \mathrm{~V}_{2} \mathrm{O}_{5}$ CSAs contacted with $\mathrm{Li} / \mathrm{Li}_{2} \mathrm{O}$, and a bias voltage of $-4.0 \mathrm{~V}$ was applied to drive $\mathrm{Li}$ ion to go through the solid-state electrolyte towards $\mathrm{NiCo}_{2} \mathrm{O}_{4} @ \mathrm{~V}_{2} \mathrm{O}_{5}$ CSAs. Figure $4 \mathrm{~b}$ shows the pristine $\mathrm{NiCo}_{2} \mathrm{O}_{4} @ \mathrm{~V}_{2} \mathrm{O}_{5}$ CSAs before the lithiation. Figure 4c shows that $\mathrm{NiCo}_{2} \mathrm{O}_{4} @ \mathrm{~V}_{2} \mathrm{O}_{5}$ CSAs went through lithiation process for $15 \mathrm{~min}$, where the coated structure continues to expand. After $30 \mathrm{~min}$ (Figure. 4d), there's negligible further expansion and this verifies that the reaction is complete. The major volumetric expansion period is in the initial $15 \mathrm{~min}$. The $c a .1 .22$ times of volume change can be detected, compared with its initial state. The delithiation process was also recorded (Figure S9) after $30 \mathrm{~min}$. Compared with its initial state, an increase thickness of the coating is due to the distortion of $\mathrm{V}_{2} \mathrm{O}_{5}$ during lithiation/delithiation. It is noted that there is no cracking or fracture in the $\mathrm{NiCo}_{2} \mathrm{O}_{4} @ \mathrm{~V}_{2} \mathrm{O}_{5}$ CSAs during the whole process of lithiation. As expected, the $\mathrm{NiCo}_{2} \mathrm{O}_{4} @ \mathrm{~V}_{2} \mathrm{O}_{5} \mathrm{CSAs}$ showed slight volumetric expansion and the $\mathrm{NiCo}_{2} \mathrm{O}_{4}$ core structure possesses sufficient ductility to accommodate the volumetric expansion, which protects the whole structure during lithiation process. The whole electrochemical process demonstrates clearly the structural stability and the excellent cycling performance of these sandwich structures. These results were in line with the SEM images before and after long term cycling.

To further understand and tackle the issue of sluggish Li diffusivity within the layered $\mathrm{V}_{2} \mathrm{O}_{5}$, we carried out theoretical calculations to study the $\mathrm{Li}$ intercalation in layered $\alpha-\mathrm{V}_{2} \mathrm{O}_{5}$ using Density Functional Theory (DFT) approaches, details of which is given in the experimental section in the supporting information. First, the simulated lattice parameters and the V-O bond distances of the $\alpha-\mathrm{V}_{2} \mathrm{O}_{5}$ structure (Figures 5a, 5b and S10) as a result of different functionals were compared with the experimental and other theoretical data and shown in Table S2. In previous calculations, the $c$ vector, the stacking direction, is heavily overestimated, even by 


\section{WILEY-VCH}

$9.98 \%,{ }^{[24,25]}$ because the van der Waals contributions are not adequately considered in the standard DFT calculations. This is in fact very important for layered structures. ${ }^{[26]}$ The discrepancy of such predictions with experimental values are indeed rather large, as shown in Table S2. Moreover, the PBEsol functional has proven to yield property predictions of densely packed materials and their surfaces. ${ }^{[27]}$ The results indeed compare favourably with experiment that the error of the lattice parameters was under $0.55 \%$. Hence, the PBEsol-vdWDF functional should be highly appropriate to predict the geometries of $\alpha-\mathrm{V}_{2} \mathrm{O}_{5}$, which is critical for further calculation as its high thermal expansion coefficients. ${ }^{[28]}$ This functional was hence selected in subsequent calculations.

The calculated electronic density of states (DOS) of $\alpha-\mathrm{V}_{2} \mathrm{O}_{5}$ are shown in Figure S10. The calculated direct band gap at Gamma point is $2.55 \mathrm{eV}$, whereas the indirect band gap is 1.98 $\mathrm{eV}$, which is consistent with previous calculations ${ }^{24}$ and experimental results. ${ }^{[29-31]}$ The partial charge density of the valence band maximum (VBM) and the conduction band minimum $(\mathrm{CBM})$ are shown in Figures $5 \mathrm{a}$ and $5 \mathrm{~b}$, where the VBM is mainly centred on vanadium, consisting of $3 \mathrm{~d}_{\mathrm{xy}}$ orbitals and the CBM is concentrated on the oxygen atoms.

Before discussion of the Li diffusion through the $\alpha-\mathrm{V}_{2} \mathrm{O}_{5}$, the stable insertion sites of $\mathrm{Li}$ in $\alpha$ $\mathrm{V}_{2} \mathrm{O}_{5}$ were studied, which are denoted as the upper and the lower hollow sites $H_{a}$ and $H_{b}$ and the top site $T$. The binding energy is calculated according to the following equation:

$E_{b}=E_{\text {total }}-\left(E_{V_{2} O_{5}}+E_{L i}\right) \quad$ Equation (4)

where $E_{\text {total }}$ is the energy of the whole system, $E_{V_{2} O_{5}}$ and $E_{L i}$ are the energies of the pristine layered $\mathrm{V}_{2} \mathrm{O}_{5}$ and the chemical energy of a single $\mathrm{Li}$, respectively. Our results (Table S3) suggest that the upper hollow site $\mathrm{H}_{\mathrm{a}}$ is all over the most stable site, followed by the top site $T$. The lower site $H_{b}$ is the least favourable site to be inserted. This conclusion is in accordance with previous work. ${ }^{[24,32]}$ Meanwhile, the layer effect also plays a role in the binding energy. 


\section{WILEY-VCH}

The deeper the $\mathrm{Li}$ is inserted, the higher the binding energy $E_{b}$. This suggests that the Li atom is keen to bind with the top layers of the $\alpha-\mathrm{V}_{2} \mathrm{O}_{5}$ slab.

As for the Li diffusion in the layered $\alpha-\mathrm{V}_{2} \mathrm{O}_{5}$, two different pathways have been considered, as illustrated in Figures 5c and 5d. Diffusion within the layers has been intensively studied in previous theoretical reports. ${ }^{[24,32,-34]}$ However, the study on the other pathway where Li diffuse across the layered $\alpha-\mathrm{V}_{2} \mathrm{O}_{5}$ has not been reported yet, neither has the layer effect on the Li diffusivity. For Li diffusion in the non-interaction lattice, the diffusion coefficient can be simply obtained through $\mathrm{D}=\Gamma \times d^{2}$, where $\Gamma$ and $d$ are the hopping frequency and hopping distance, respectively. ${ }^{[35]}$ Further by adopting the Arrhenius theory and the transition state theory, the equation of diffusivity can be put together in the following equation: ${ }^{[36]}$

$D=d^{2} v^{*} e^{-\frac{E_{\text {act }}}{k_{B} T}}$

Equation (5)

where $E_{a c t}$ is the activation energy, $v^{*}$ is the attempt frequency, $k_{B}$ and $T$ are the Boltzmann constant and temperature respectively. As for the activation energy $E_{a c t}$ of a $\mathrm{Li}$ atom to diffuse through the $\alpha-\mathrm{V}_{2} \mathrm{O}_{5}$, it can be simplified as the energy barrier along the diffusion pathway. Whereas the attempt frequency $v^{*}$ is generally in the range of phonon frequencies. ${ }^{[37]}$ This is adopted from the experimental data of the literature ${ }^{[38]}$, where $v *=3.1 \times 10^{13} \mathrm{~Hz}$.

The simulated Li average diffusivities along the two different pathways for few layers $\alpha-\mathrm{V}_{2} \mathrm{O}_{5}$ are shown in Figure 5e. Overall, the in-plane diffusivity is far higher than the inter-plane intercalation by 12 orders of magnitude. The in-plane diffusivity varies exponentially with the thickness, $\sim e^{0.4835 x}$, where $\mathrm{x}$ is the thickness of $\mathrm{V}_{2} \mathrm{O}_{5}$ layers. As for individual diffusivity in different layers, the intercalation along the top layer possesses the highest diffusivity. This is due to the lower energy penalty needed to hop from one hollow position to another within the same layer on the surface of the $\alpha-\mathrm{V}_{2} \mathrm{O}_{5}$ slab. As the layer thickness increases, the binding 


\section{WILEY-VCH}

energy and energy barrier of Li drops, leading to an increased diffusion rate on the surface. As for intercalation in the middle of the slides, the diffusivity drops considerably. The situation is similar to the bulk, where the Li binds to both the upper and the lower layers. Even though the over-all diffusivity is dominated by the in-plane pathway, the inter-plane diffusion plays the key role in incorporating more $\mathrm{Li}$ from the solution into the layered $\alpha-\mathrm{V}_{2} \mathrm{O}_{5}$, i.e. contributing to capacity. Our results show that the inter-plane diffusion is declined by $\sim x^{-3.3474}$. And two formulas were fitted according to the simulated results of 5 layers of $\alpha-\mathrm{V}_{2} \mathrm{O}_{5}$ in Table S4.

As calculated from the high magnification SEM images of $\mathrm{NiCo}_{2} \mathrm{O}_{4} @ \mathrm{~V}_{2} \mathrm{O}_{5}$ CSAs and 3D $\mathrm{NiCo}_{2} \mathrm{O}_{4}$ nanosheets arrays (Figure $\mathrm{S} 12$ ), the thickness of the outer layers of $\mathrm{V}_{2} \mathrm{O}_{5}$ from $3 \mathrm{D}$ sandwich structures are $\sim 32.6 \mathrm{~nm}$, which is equivalent to $\sim 77$ atomic layers of $\mathrm{V}_{2} \mathrm{O}_{5}$. The corresponding inter-plane diffusivity of $\mathrm{Li}$ for the innermost layer can be estimated as $3.72 \times 10^{-26} \mathrm{~cm}^{2} \mathrm{~S}^{-1}$. The ideal relationship between the thickness of the $\mathrm{V}_{2} \mathrm{O}_{5}$ layers and the specific capacity is shown in Figure 5f. The mass of the conductive and supporting frameworks with negligible contributions to specific capacity, i.e. 3D networked $\mathrm{NiCO}_{2} \mathrm{O}_{4}$, was summed with active materials. With the increase of thickness of the $\mathrm{V}_{2} \mathrm{O}_{5}$ active materials and keeping the mass of the frameworks constant, the mass loading would increase sharply and the sum of the specific capacity can approach the theoretical values of the $\mathrm{V}_{2} \mathrm{O}_{5}$ even without considering the Li diffusion limitations and electrical conductivity. Obviously, the rapid decline of diffusion of $\mathrm{Li}$ within $\mathrm{V}_{2} \mathrm{O}_{5}$ layers is the main limitation for realizing the theoretical specific capacity. In this 3D sandwich structures, the above calculated inter-plane diffusivity value together with the enhanced electrical conductivity (Figure S13, 14 and Table S5) can guarantee the realizing of theoretical specific capacity at the current density of $0.1 \mathrm{C}$.

In summary, a targeted functional design of sandwich-structural 3D $\mathrm{NiCo}_{2} \mathrm{O}_{4} @ \mathrm{~V}_{2} \mathrm{O}_{5} \mathrm{CSAs}$ on carbon cloth as the cathode for LIBs have been balanced the major issues in the cathode 


\section{WILEY-VCH}

improvements and shown excellent specific capacity of $\sim 292.0 \mathrm{~mA} \mathrm{~h} \mathrm{~g}^{-1}$ at a current density of $0.1 \mathrm{C}$, superior rate capability of $\sim 45 \%$ retention when the current density was increased 200 times based on the total mass of active materials and frameworks and one of the best reported cycling performances of $0.0126 \%$ capacity decrease per cycle over 500 cycles. The rational structure design was proved from both in-situ TEM and theoretical simulation works. The DFT calculations gave the quantum level insights of the layer effect on the Li diffusion in the layered $\alpha-\mathrm{V}_{2} \mathrm{O}_{5}$. By studying the few layer slides of both in-plane and inter-plane pathway, our results suggest that the speed of diffusivity of $\mathrm{Li}$ is dominated by the in-plane direction, whereas inter-plane direction diffusion affects further more Li intercalation. The balance of the Li diffusivity and the specific capacity of the electrode materials can reach to an optimized level. The impact of this work is that it can expand the scope of the design concept of nanostructures for electrodes for batteries and shows that layered $\mathrm{V}_{2} \mathrm{O}_{5}$ nanostructures have an exciting future for LIBs cathodes application.

\section{Acknowledgements}

G. He. and X. Han contributed equally to this work. University College London and China Scholarship Council are acknowledged for UCL-CSC joint Ph.D scholarship. UCL Doctoral School is acknowledged for Yale-UCL Collaborative Bursary. The authors would like to thank the financial support from Engineering and Physical Sciences Research Council (EPSRC), the "Pujiang" Program of Shanghai Education Commission (Grant No. 16PJ1400200), National Natural Science Foundation of China (Grant No. 51672044) and DHU Distinguished Young Professor Program to carry out the experiments and our membership of the UK's HPC Materials Chemistry Consortium, which is funded by EPSRC (EP/L000202). The authors would also thank the use of the UCL Grace High Performance Computing Facility and associated support services, in the completion of this work. 


\section{Supporting Information}

\section{WILEY-VCH}

Supporting Information is available online from the Wiley Online Library or from the author.

Received: ((will be filled in by the editorial staff))

Revised: ((will be filled in by the editorial staff))

Published online: ((will be filled in by the editorial staff))

\section{References:}

[1] J. -M. Tarascon, M. Armand, Nature 2001, 414, 359.

[2] V. Etacheri, R. Marom, R. Elazari, G. Salitra, D. Aurbach, Energy Environ. Sci. 2011, $4,3243$.

[3] D. Chao, X. Xia, J. Liu, Z. Fan, C. F. Ng, J. Lin, H. Zhang, Z. X. Shen, H. J. Fan, Adv. Mater. 2014, 26, 5794.

[4] D. Kong, X. Li, Y. Zhang, X. Hai, B. Wang, X. Qiu, Q. Song, Q.-H. Yang, L. Zhi, Energy Environ. Sci. 2016, 9, 906.

[5] X. Peng, X. Zhang, L. Wang, L. Hu, S. H.-S. Cheng, C. Huang, B. Gao, F. Ma, K. Huo, P. K. Chu, Adv. Funct. Mater. 2016, 26, 784.

[6] Q. Liu, Z. F. Li, Y. Liu, H. Zhang, Y. Ren, C. J. Sun, W. Lu, Y. Zhou, L. Stanciu, E. A. Stach, J. Xie, Nat. Commun. 2015, 6, 6127.

[7] X. Rui, Y. Tang, O. I. Malyi, A. Gusak, Y. Zhang, Z. Niu, H. T. Tan, C. Persson, X. Chen, Z. Chen, Q. Yan, Nano Energy 2016, 22, 583.

[8] M. Chen, X. Xia, J. Yuan, J. Yin, Q. Chen, J. Power Sources 2015, 288, 145.

[9] X. Rui, Z. Lu, H. Yu, D. Yang, H. H. Hng, T. M. Lim, Q. Yan, Nanoscale, 2013, 5, 556.

[10] S. Wang, Z. Lu, D. Wang, C. Li, C. Chen, Y. Yin, J. Mater. Chem. 2011, 21, 6365.

[11] S. Liang, Y. Hu, Z. Nie, H. Huang, T. Chen, A. Pan, G. Cao, Nano Energy 2015, 13, 


\section{WILEY-VCH}

58.

[12] G. Yang, H. Song, M. Wu, C. Wang, Electrochim. Acta 2016, 205, 153.

[13] M. Ihsan, Q. Meng, L. Li, D. Li, H. Wang, K. H. Seng, Z. Chen, S. J. Kennedy, Z. Guo, H.-K. Liu, Electrochim. Acta 2015, 173, 172.

[14] R. Zou, Z. Zhang, M. F. Yuen, M. Sun, J. Hu, C.-S. Lee, W. Zhang, NPG Asia Mater. 2015, 7, e195.

[15] G. He, J. Li, W. Li, B. Li, N. Noor, K. Xu, J. Hu, I. P. Parkin, J. Mater. Chem. A 2015, 3,14272 .

[16] G. Kucinskis, G. Bajars, J. Kleperis, J. Power Sources 2013, 240, 66.

[17] L. Zhan, S. Wang, L.-X. Ding, Z. Li, H. Wang, J. Mater. Chem. A 2015, 3, 19711.

[18] B. Sun, K. Huang, X. Qi, X. Wei, J. Zhong, Adv. Funct. Mater. 2015, 25, 5633.

[19] B. Yan, X. Li, Z. Bai, Y. Zhao, L. Dong, X. Song, D. Li, C. Langford, X. Sun, Nano Energy 2016, 24, 32.

[20] H. Song, C. Zhang, Y. Liu, C. Liu, X. Nan, G. Cao, J. Power Sources 2015, 294, 1.

[21] M. Castriota, E. Cazzanelli, A. Fasanella, D. Teeters, Thin Solid Films 2014, 553, 127.

[22] H. Yu, X. Rui, H. Tan, J. Chen, X. Huang, C. Xu, W. Liu, D. Y. Yu, H. H. Hng, H. E. Hoster, Q. Yan, Nanoscale 2013, 5, 4937.

[23] G. Q. Zhang, H. B. Wu, H. E. Hoster, M. B. Chan-Park, X. W. Lou, Energy Environ. Sci. 2012, 5, 9453.

[24] J. Carrasco, J. Phys. Chem. C 2014, 118, 19599.

[25] D. O. Scanlon, A. Walsh, B. J. Morgan, G. W. Watson, J. Phys. Chem. C 2008, 112, 9903.

[26] X. Han, H. M. Stewart, S. A. Shevlin, C. R. Catlow, Z. X. Guo, Nano Lett. 2014, 14, 4607.

[27] J. P. Perdew, A. Ruzsinszky, G. I. Csonka, O. A. Vydrov, G. E. Scuseria, L. A. Constantin, X. Zhou, K. Burke, Phys. Rev. Lett. 2008, 100, 136406. 


\section{WILEY-VCH}

[28] J. J. Krochmal, J. Am. Ceram. Soc. 1965, 48, 328.

[29] N. V. Hieu, J. Vac. Sci. Technol. 1981, 18, 49.

[30] S. F. Cogan, N. M. Nguyen, S. J. Perrotti, R. D. Rauh, J. Appl. Phys. 1989, 66, 1333.

[31] A. Z. Moshfegh, A. Ignatiev, A. Thin Solid Films 1991, 198, 251.

[32] Z. Wang, Q. Su, H. Deng, Phys. Chem. Chem. Phys. 2013, 15, 8705.

[33] G. S. Gautam, P. Canepa, R. Malik, M. Liu, K. Persson, G. Ceder, Chem. Commun. (Camb.) 2015, 51, 13619-13622.

[34] W. Y. Ma, B. Zhou, J. F. Wang, X. D. Zhang, Z. Y. Jiang, J. Phys. D: Appl. Phys. 2013, 46, 105306.

[35] R. Kutner, Phys. Lett. A 1981, 81A, 239.

[36] K. A. Connors, Wiley 1990.

[37] G. H. Vineyard, J. Phys. Chem. Solids 1957, 3, 121.

[38] P. Clauws, J. Vennik, Phys. Stat. Sol. B 1976, 76, 707. 


\section{WILEY-VCH}
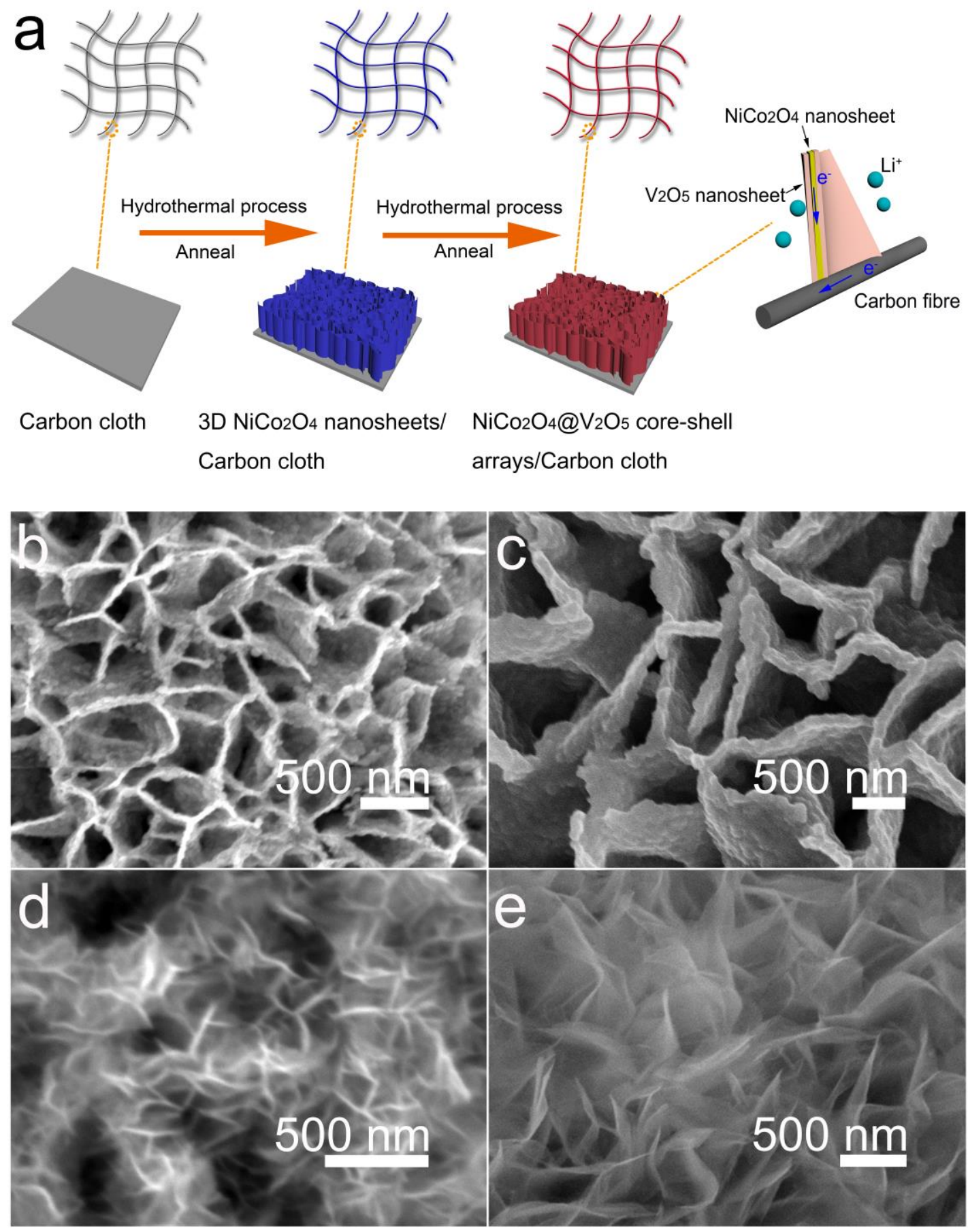

\section{$500 \mathrm{~nm}$}

Figure 1. Synthesis procedure and the morphologies of the products. (a) Schematic illustration of the synthesis process for $\mathrm{NiCo}_{2} \mathrm{O}_{4} @ \mathrm{~V}_{2} \mathrm{O}_{5}$ core-shell arrays (CSAs) on carbon cloth; (b-e) SEM images of four $\mathrm{NiCo}_{2} \mathrm{O}_{4} @ \mathrm{~V}_{2} \mathrm{O}_{5}$ CSAs on carbon cloth with different reaction solution concentrations $(\mathrm{b}: 0.1 \mathrm{~mL}$, c: $0.2 \mathrm{~mL}, \mathrm{~d}: 0.3 \mathrm{~mL}$ and e: $0.4 \mathrm{~mL}$ of vanadium oxytriisopropoxide, respectively) in the second hydrothermal process of (a). 


\section{WILEY-VCH}

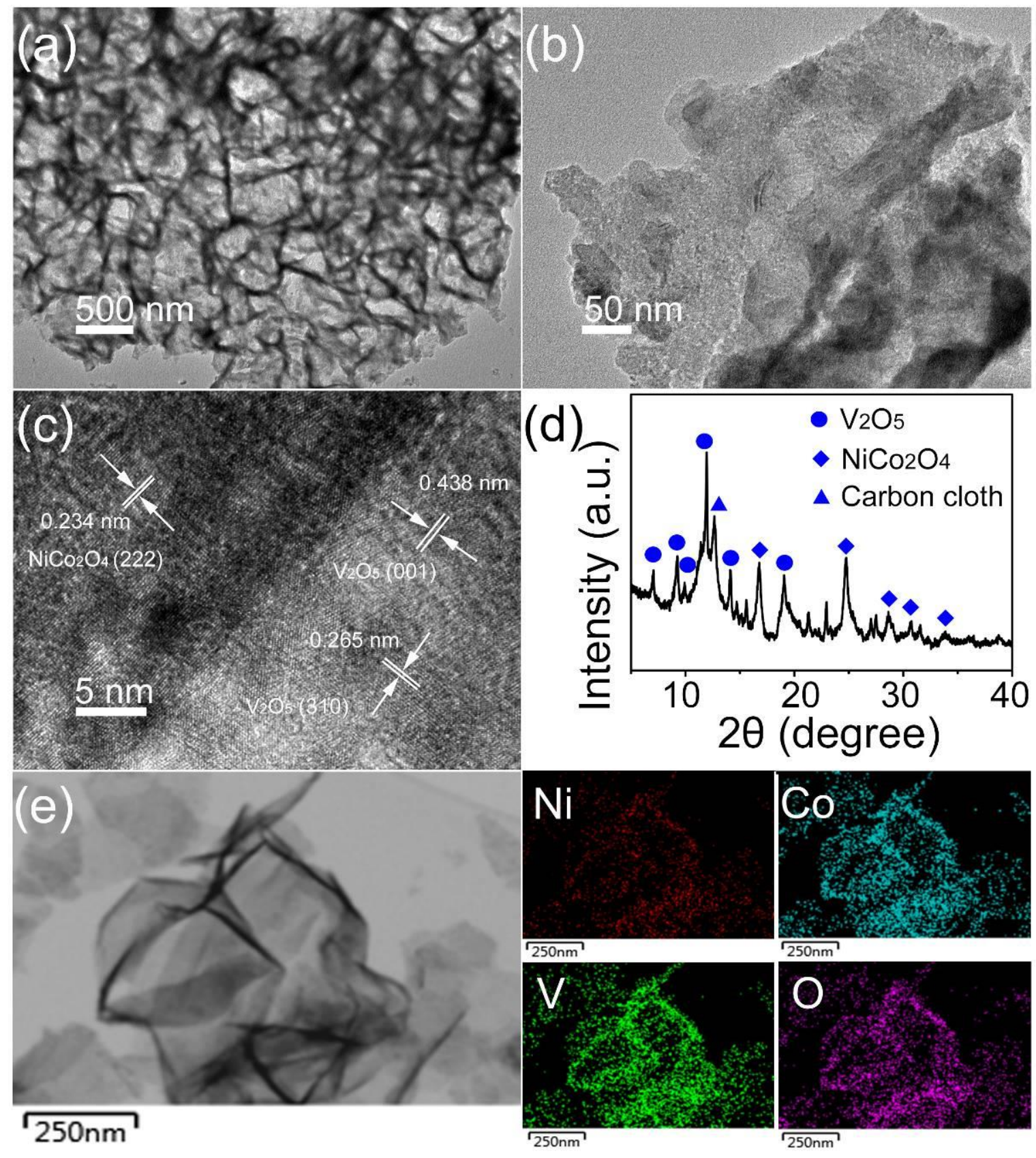

Figure 2. Structural characterization of the $\mathrm{NiCo}_{2} \mathrm{O}_{4} @ \mathrm{~V}_{2} \mathrm{O}_{5}$ CSAs. (a) Low and (b) high magnification TEM images of $\mathrm{NiCo}_{2} \mathrm{O}_{4} @ \mathrm{~V}_{2} \mathrm{O}_{5}$ CSAs; (c) High resolution TEM images of $\mathrm{NiCo}_{2} \mathrm{O}_{4} @ \mathrm{~V}_{2} \mathrm{O}_{5} \mathrm{CSAs}$; (d) XRD pattern of $\mathrm{NiCo}_{2} \mathrm{O}_{4} @ \mathrm{~V}_{2} \mathrm{O}_{5} \mathrm{CSAs} /$ carbon cloth; (e) TEM images with corresponding elemental maps. 
WILEY-VCH
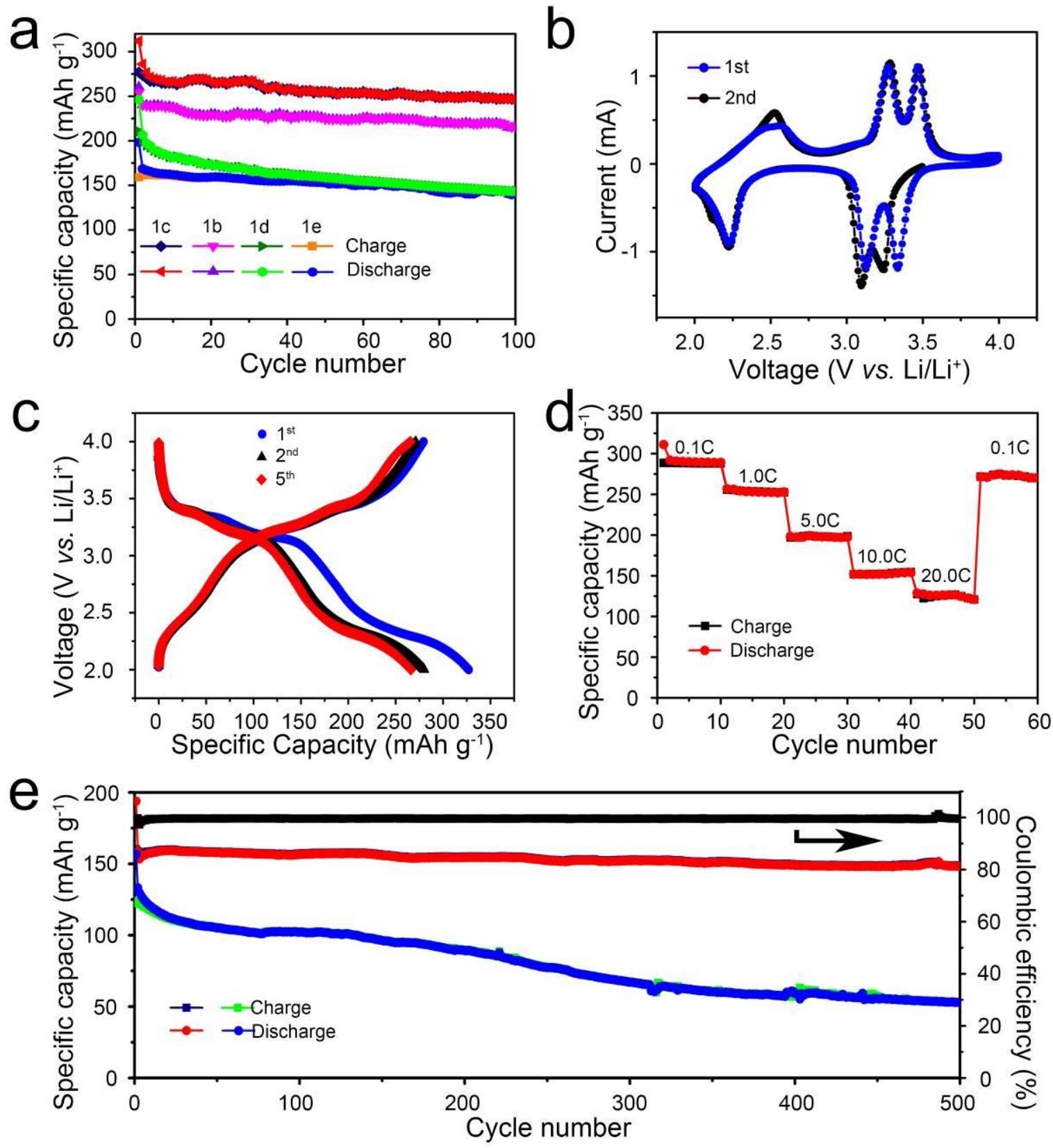

Figure 3. Electrochemical performances over the $\mathrm{NiCo}_{2} \mathrm{O}_{4} @ \mathrm{~V}_{2} \mathrm{O}_{5} \mathrm{CSAs}$ as cathodes for

LIBs. (a) Cycling performances of four $\mathrm{NiCo}_{2} \mathrm{O}_{4} @ \mathrm{~V}_{2} \mathrm{O}_{5} \mathrm{CSAs}$ at a current density of $0.5 \mathrm{C}$ (1b, 1c, 1d and 1e corresponding to different samples in Figure 1b, 1c, 1d and 1e); (b) Cyclic voltammetry (CV) test of $\mathrm{NiCo}_{2} \mathrm{O}_{4} @ \mathrm{~V}_{2} \mathrm{O}_{5} \mathrm{CSAs}$ at a scan rate of $0.1 \mathrm{mV} \mathrm{s}^{-1}$; (c) Chargedischarge curves (CD) of $\mathrm{NiCo}_{2} \mathrm{O}_{4} @ \mathrm{~V}_{2} \mathrm{O}_{5}$ CSAs at a current density of 0.1C. (d) Rate performances of $\mathrm{NiCo}_{2} \mathrm{O}_{4} @ \mathrm{~V}_{2} \mathrm{O}_{5} \mathrm{CSAs}$ at various current densities; (e) Cycling performance and corresponding Coulombic efficiency of $\mathrm{NiCo}_{2} \mathrm{O}_{4} @ \mathrm{~V}_{2} \mathrm{O}_{5}$ CSAs and cycling performance of $\mathrm{V}_{2} \mathrm{O}_{5}$ nanoparticles measured at high current density of $10 \mathrm{C}$. 


\section{WILEY-VCH}

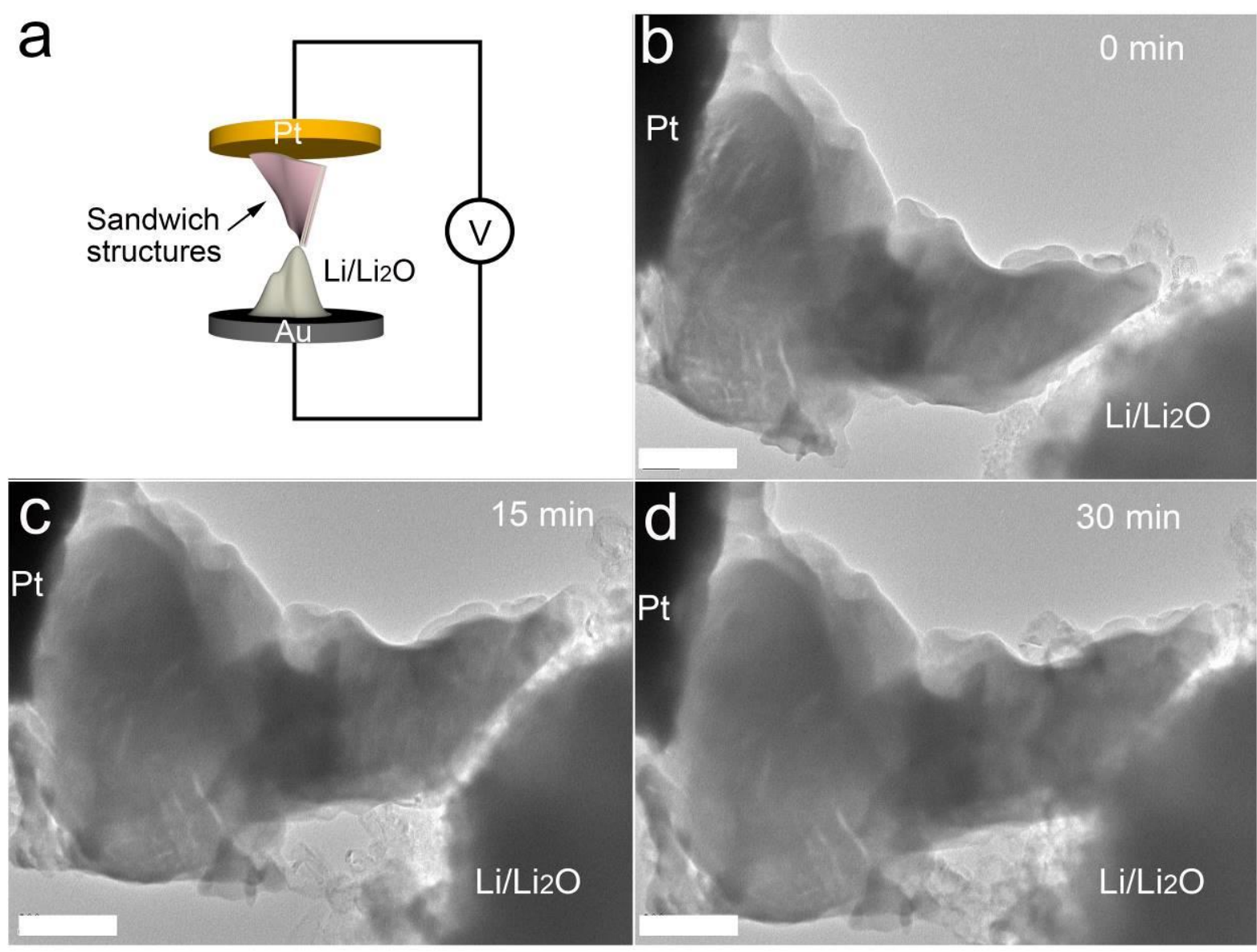

Figure 4. Structural design discussion based on in-situ TEM. (a) Schematic diagram showing the configuration of in-situ TEM observations of the lithiation process; (b-d) TEM images monitoring the lithiation process of the $\mathrm{NiCo}_{2} \mathrm{O}_{4} @ \mathrm{~V}_{2} \mathrm{O}_{5} \mathrm{CSAs}$ at 0,15 and $30 \mathrm{~min}$, respectively (Scale bar: $500 \mathrm{~nm}$ ). 


\section{WILEY-VCH}
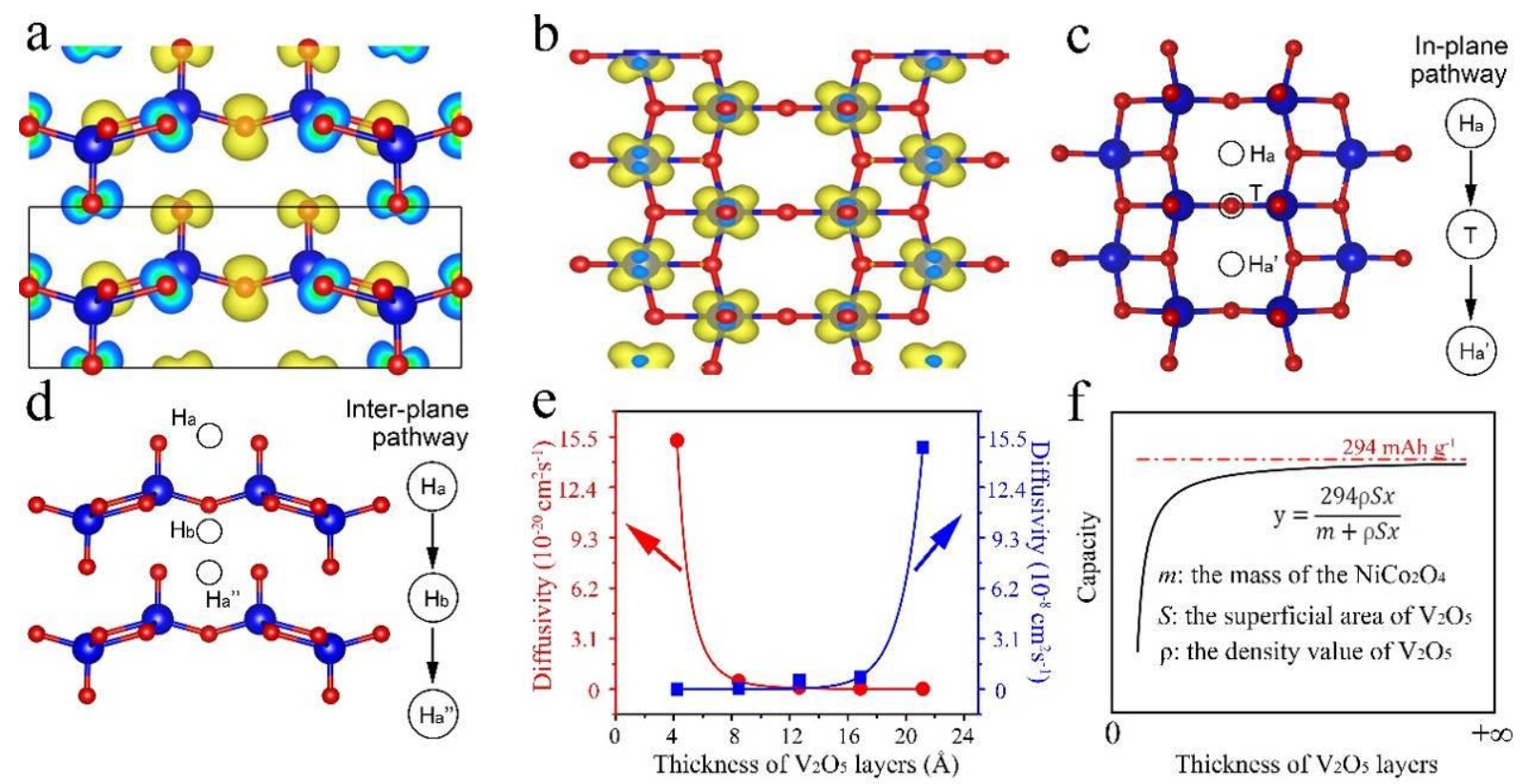

Figure 5. Optimal energy storage performances design analysis from Li diffusivity. (a, b)

The side-view and top-view of $\alpha-\mathrm{V}_{2} \mathrm{O}_{5}$ with the partial charge density of the valence band maximum (a) and conduction band minimum (b). The isosurface is set to $0.01 \mathrm{e} / \mathrm{a}_{0}{ }^{3}$. (blue ball: vanadium atom, red ball: oxygen atom) (c, d) Diagrams of the two possible pathways for Li within layered $\alpha-\mathrm{V}_{2} \mathrm{O}_{5}$. (c) in-plane pathway from hollow position $\left(\mathrm{H}_{\mathrm{a}}\right)$ to another hollow position $\left(\mathrm{H}_{\mathrm{a}}^{\prime}\right)$ through top position $(\mathrm{T})$; (d) inter-plane pathway from the hollow position in the upper layer $\left(\mathrm{H}_{\mathrm{a}}\right)$ to the lower layer $\left(\mathrm{H}_{\mathrm{a}}{ }^{\prime}\right)$; (e) The diffusivity of Li through in-plane (blue line) and inter-plane (red line) pathways as a function of the thickness of $\alpha-\mathrm{V}_{2} \mathrm{O}_{5}$; (f) theoretical relationship of specific capacity with the change of the thickness of the layered $\alpha-$ $\mathrm{V}_{2} \mathrm{O}_{5}$ assuming the case of two Li intercalation/de-intercalation. 


\section{WILEY-VCH}

The table of contents entry

The targeted functional 3D NiCo $2 \mathrm{O}_{4} @ \mathrm{~V}_{2} \mathrm{O}_{5}$ core-shell sandwich arrays on carbon cloth for rechargeable Li-ion battery have realized theoretical limits of specific capacity and high stability over 500 cycles. The superb performance relies on its structural nano-architecture by separated pathways for lithiation process and conduction. The thickness of the active material is optimized, guided by theoretical study.

Keyword: 3D sandwich arrays, Li-ion battery, Cathodes, Density Functional Theory (DFT), In-situ TEM

Title

A Targeted Functional Design for Highly Efficient and Stable Cathodes for Rechargeable Li-Ion Batteries

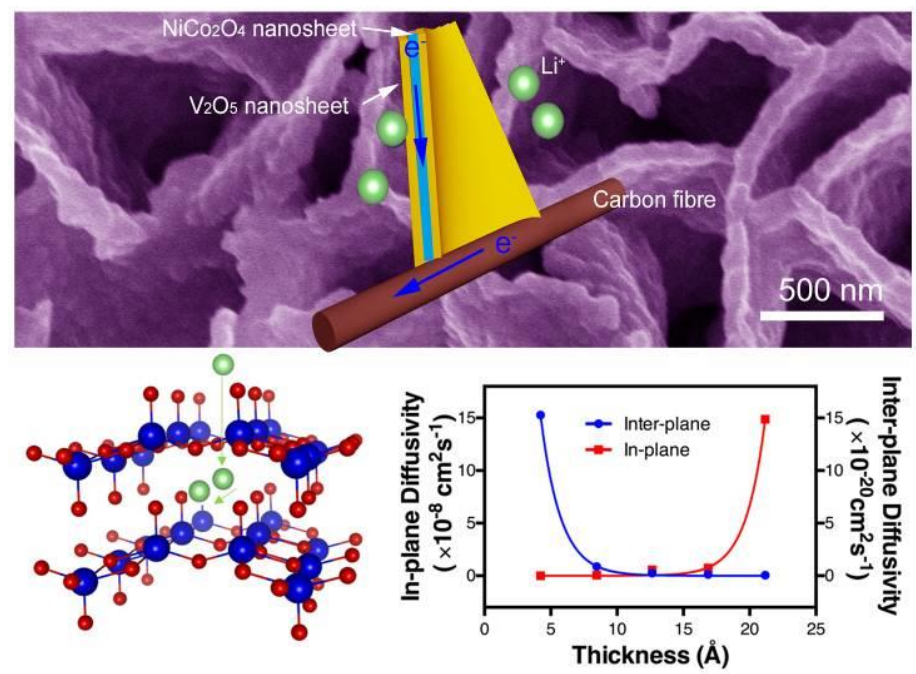

Copyright WILEY-VCH Verlag GmbH \& Co. KGaA, 69469 Weinheim, Germany, 2013. 


\section{WILEY-VCH}

\section{Supporting Information}

for Adv. Mater., DOI: 10.1002/adma.((please add manuscript number))

\section{A Targeted Functional Design for Highly Efficient and Stable Cathodes for Rechargeable Li-Ion Batteries}

Guanjie He ${ }^{a, c}$, Xiaoyu Han ${ }^{a}$, Rujia Zou ${ }^{b, *}$, Tingting Zhao ${ }^{a}$, Zhe Weng ${ }^{c}$, SocMan Ho-Kimura ${ }^{a}$, Yao Lu ${ }^{a}$, Hailiang Wang ${ }^{c}$, Zheng Xiao Guo and Ivan P. Parkin ${ }^{a}$ *

Guanjie He, Dr. Xiaoyu Han, Tingting Zhao, Dr. SocMan Ho-Kimura, Yao Lu, Prof. Zheng Xiao Guo, Prof. Ivan P. Parkin

${ }^{a}$ Christopher Ingold Laboratory, Department of Chemistry, University College London, 20 Gordon Street, London WC1H OAJ, U.K.,

E-mail:i.p.parkin@ucl.ac.uk

Prof. Rujia Zou

${ }^{b}$ State Key Laboratory for Modification of Chemical Fibers and Polymer Materials, College of Materials Science and Engineering, Donghua University, Shanghai 201620, China, Email:rjzou@dhu.edu.cn

Guanjie He, Dr. Zhe Weng, Prof. Hailiang Wang

${ }^{c}$ Department of Chemistry and Energy Sciences Institute, Yale University, 810 West Campus Drive, West Haven, Connecticut 06516, U.S.A. 


\section{WILEY-VCH}
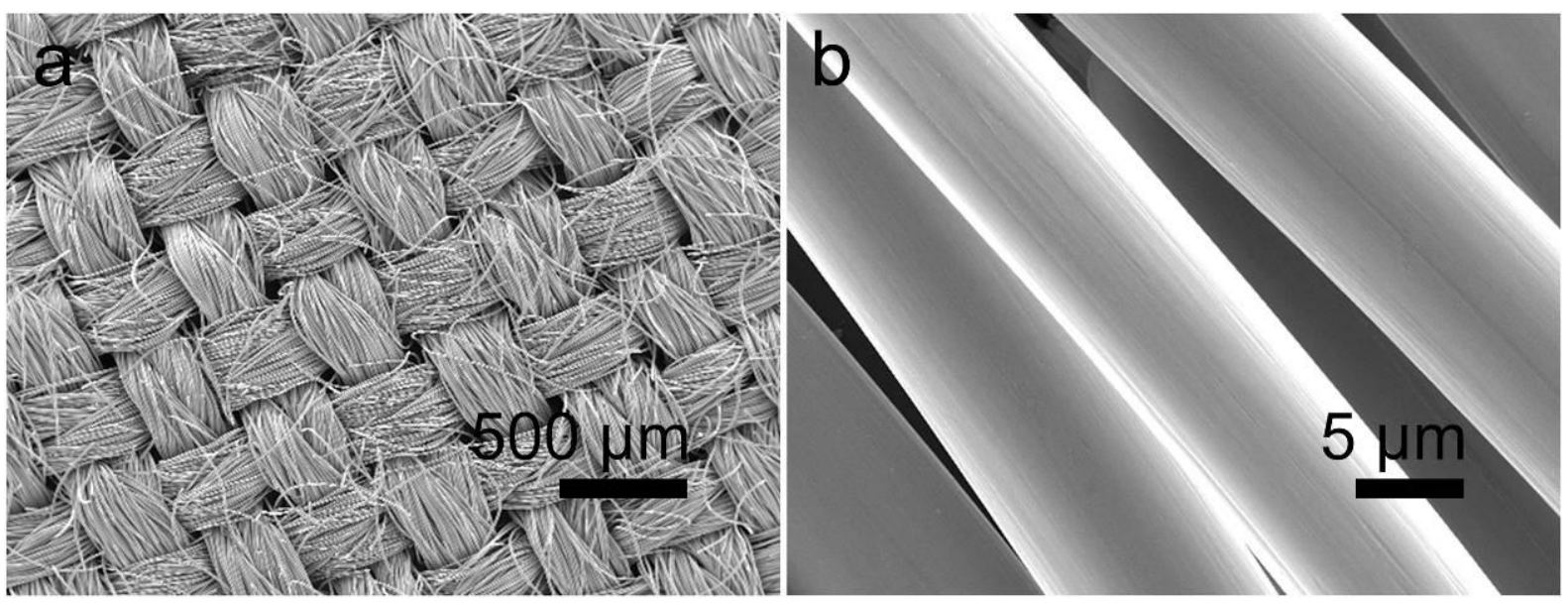

Figure S1. Low and high magnification SEM of the carbon cloth.

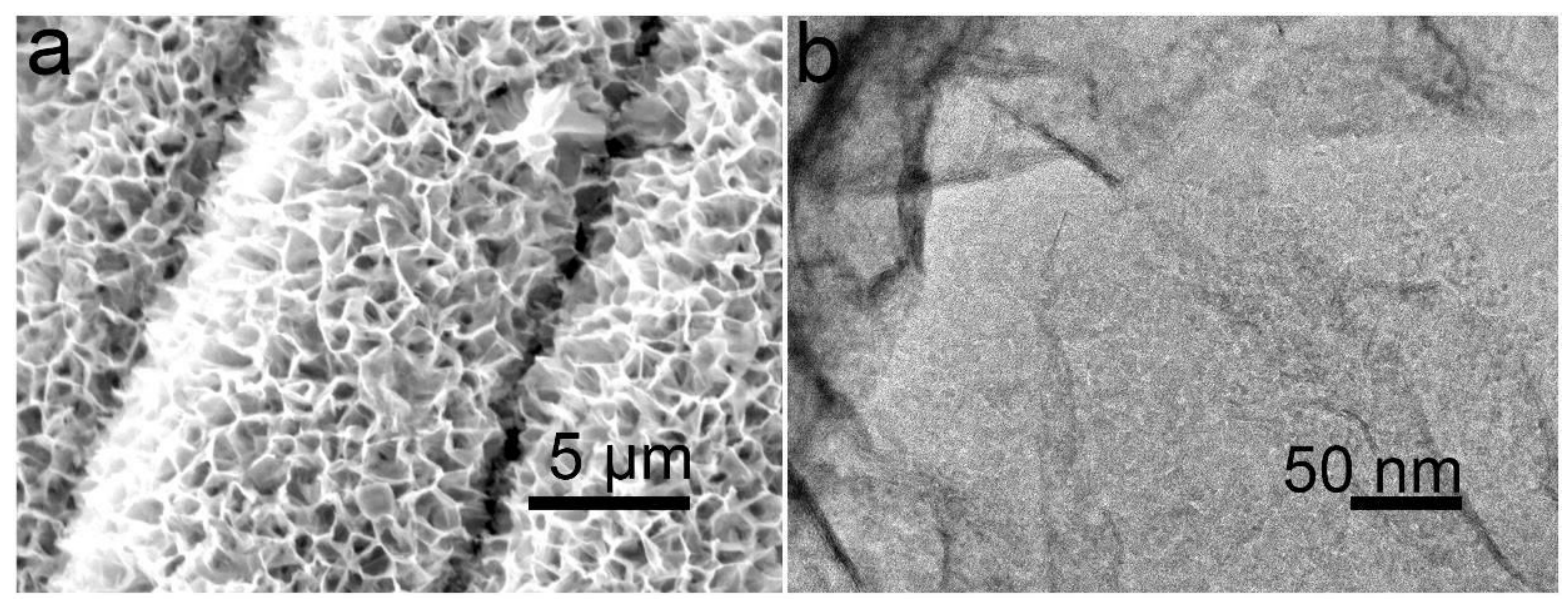

Figure S2. (a) SEM image of the $\mathrm{NiCo}_{2} \mathrm{O}_{4}$ nanoarrays/carbon cloth; (b) TEM images of $\mathrm{NiCo}_{2} \mathrm{O}_{4}$ nanosheet. 


\section{WILEY-VCH}

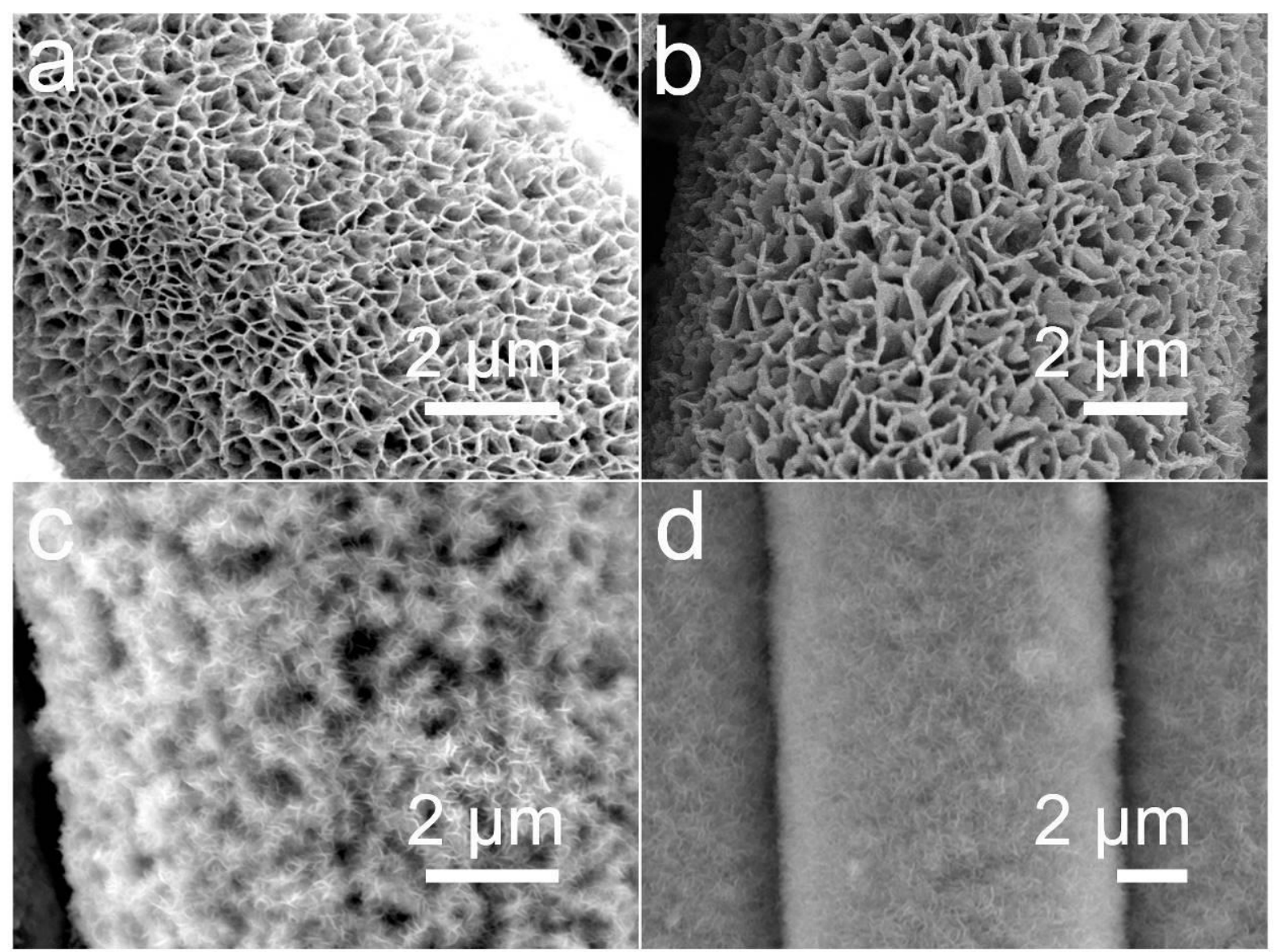

Figure S3. Low magnification SEM image of four kinds of $\mathrm{NiCo}_{2} \mathrm{O}_{4} @ \mathrm{~V}_{2} \mathrm{O}_{5} \mathrm{CSAs} /$ carbon cloth.
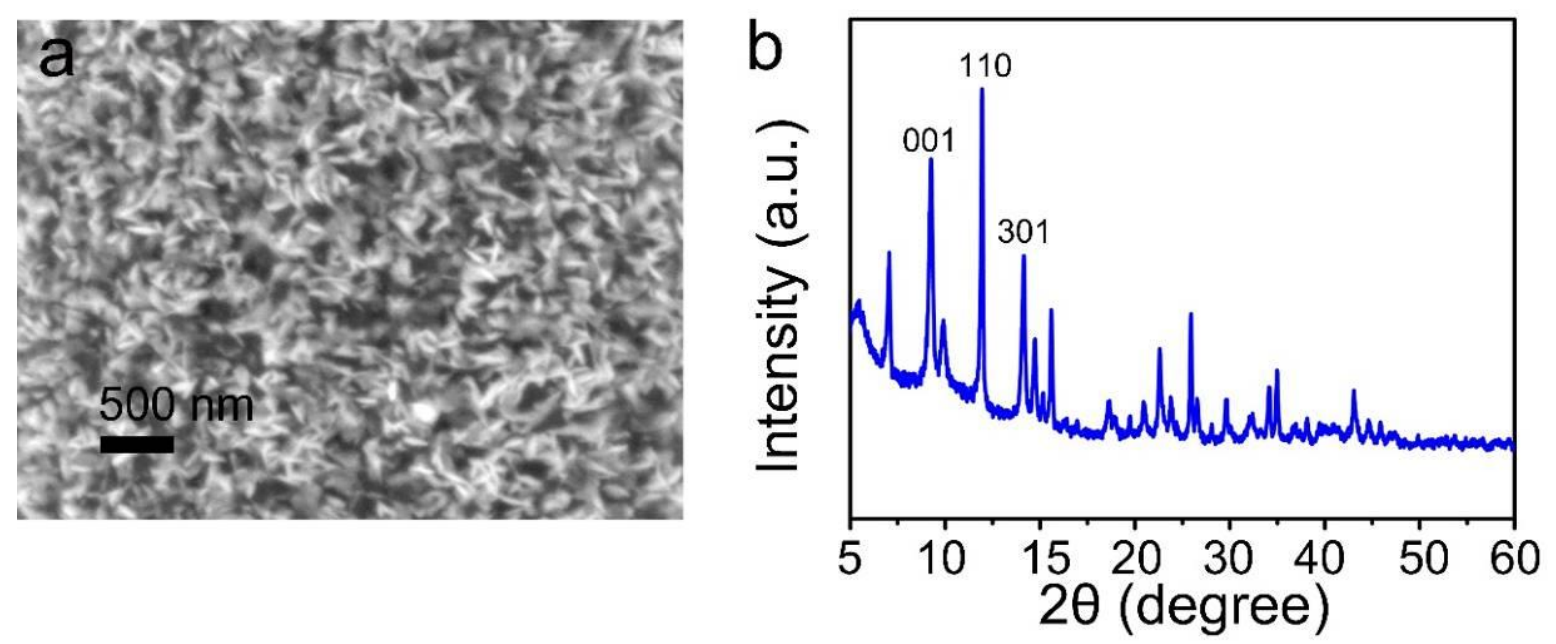

Figure S4. (a) SEM image of $\mathrm{V}_{2} \mathrm{O}_{5}$ nanoparticles; (b) XRD pattern of $\mathrm{V}_{2} \mathrm{O}_{5}$ nanoparticles. 
WILEY-VCH
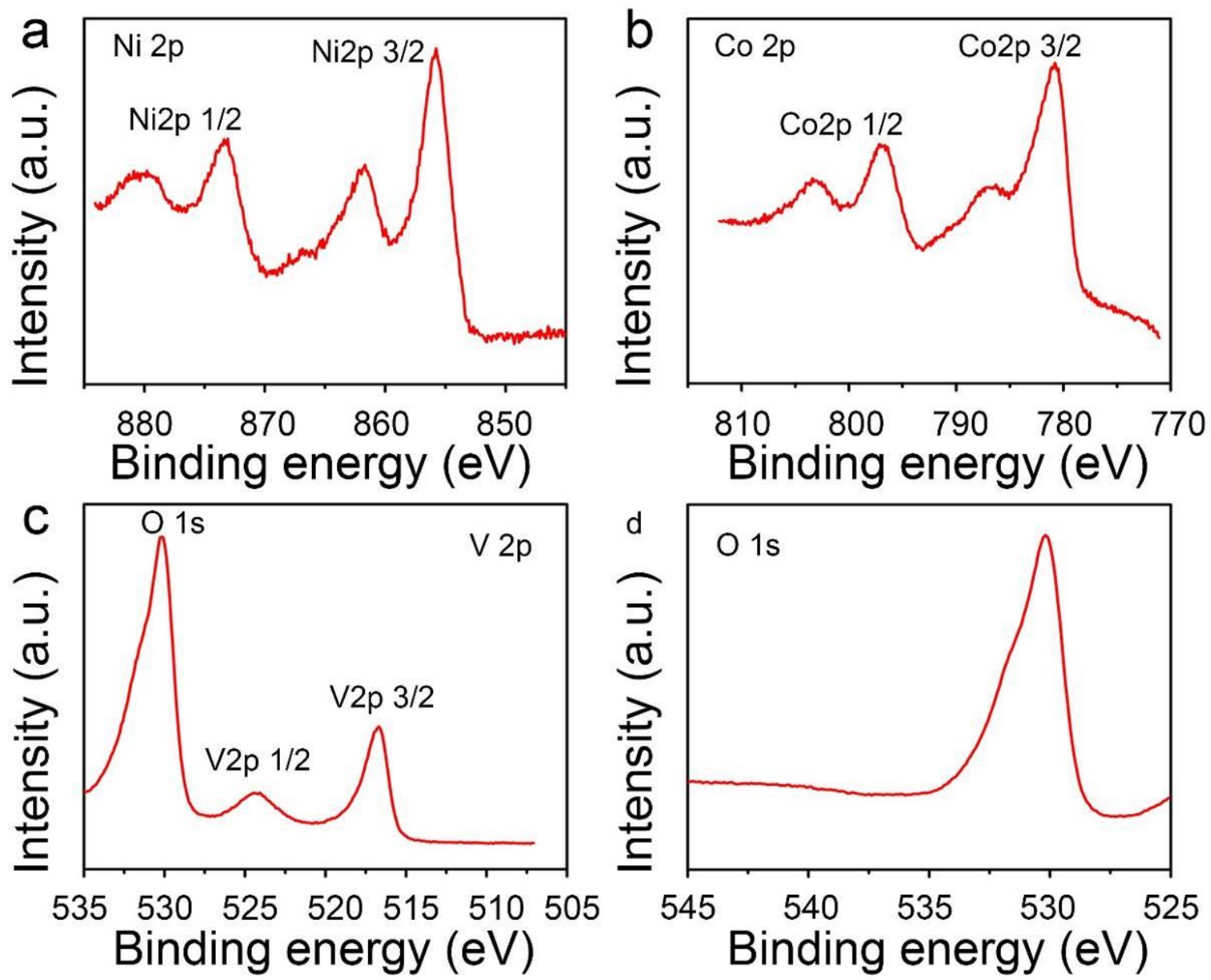

Figure S5. XPS spectra of (a) Ni 2p; (b) Co 2p; (c) V 2p and (d) O 1s. 


\section{WILEY-VCH}

Table S1. Comparison of energy storage performances of $\mathrm{NiCo}_{2} \mathrm{O}_{4} @ \mathrm{~V}_{2} \mathrm{O}_{5}$ SAs/carbon cloth as cathodes in LIBs with the representative cathodes in the literature.

\begin{tabular}{|c|c|c|c|c|}
\hline Cathodes for LIBs & $\begin{array}{l}\text { Specific } \\
\text { capacity } \\
\text { (Current } \\
\text { density) }\end{array}$ & $\begin{array}{l}\text { Rate } \\
\text { performances } \\
\text { (Increased } \\
\text { current density) }\end{array}$ & Stability & Ref. \\
\hline $\begin{array}{l}\mathrm{NiCo}_{2} \mathrm{O}_{4} @ \mathrm{~V}_{2} \mathrm{O}_{5} \\
\text { CSAs/carbon cloth }\end{array}$ & $\begin{array}{l}292 \mathrm{mAh} \mathrm{g}^{-1} \\
(0.1 \mathrm{C})\end{array}$ & $\begin{array}{l}45 \% \text { retention } \\
(200 \text { times })\end{array}$ & $\begin{array}{l}0.0126 \% \text { decrease per cycle } \\
(500 \text { cyles at } 10 \mathrm{C})\end{array}$ & $\begin{array}{l}\text { This } \\
\text { work }\end{array}$ \\
\hline $\mathrm{V}_{2} \mathrm{O}_{5}$ nanobelts & $\begin{array}{l}280 \mathrm{mAh} \mathrm{g}^{-1} \\
(0.2 \mathrm{C})\end{array}$ & $\begin{array}{l}32 \% \text { retention } \\
(200 \text { times })\end{array}$ & $\begin{array}{l}0.28 \% \text { decrease per cycle } \\
(50 \text { cycles at } 0.2 \mathrm{C})\end{array}$ & {$[1]$} \\
\hline $\begin{array}{l}\mathrm{V}_{2} \mathrm{O}_{5} @ \text { carbon } \\
\text { nanotubes }\end{array}$ & $\begin{array}{l}224 \mathrm{mAh} \mathrm{g}^{-1} \\
(0.1 \mathrm{C})\end{array}$ & $\begin{array}{l}40.2 \% \text { retention } \\
(1000 \text { times })\end{array}$ & $\begin{array}{l}0.0415 \% \text { decrease per cycle } \\
(200 \text { cycle at } 0.5 \mathrm{C})\end{array}$ & [2] \\
\hline $\begin{array}{l}\text { Porous } \\
\text { microspheres }\end{array}$ & $\begin{array}{l}275 \mathrm{mAh} \mathrm{g}^{-1} \\
(0.125 \mathrm{C})\end{array}$ & $\begin{array}{l}33.5 \% \text { retention } \\
\text { (120 times) }\end{array}$ & $\begin{array}{l}0.38 \% \text { decrease per cycle } \\
(20 \text { cycles at } 0.2 \mathrm{C})\end{array}$ & [3] \\
\hline $\begin{array}{l}\mathrm{V}^{4+}-\mathrm{V}_{2} \mathrm{O}_{5} \\
\text { nanoflake }\end{array}$ & $\begin{array}{l}293 \mathrm{mAh} \mathrm{g}^{-1} \\
\left(100 \mathrm{~mA} \mathrm{~g}^{-1}\right)\end{array}$ & $\begin{array}{l}47.4 \% \text { retention } \\
(40 \text { times) }\end{array}$ & $\begin{array}{l}0.05 \% \text { decrease per cycle } \\
\left(100 \text { cycles at } 2000 \mathrm{mAh} \mathrm{g}^{-1}\right)\end{array}$ & [4] \\
\hline $\mathrm{V}_{2} \mathrm{O}_{5}$ nanosheets & $\begin{array}{l}141 \mathrm{mAh} \mathrm{g}^{-1} \\
\left(100 \mathrm{~mA} \mathrm{~g}^{-1}\right)\end{array}$ & $\begin{array}{l}88 \% \text { retention } \\
(60 \text { times })\end{array}$ & $\begin{array}{l}0.09 \% \text { decrease per cycle } \\
\left(100 \text { cycles at } 100 \mathrm{mAh} \mathrm{g}^{-1}\right)\end{array}$ & {$[5]$} \\
\hline $\begin{array}{l}\mathrm{LiNi}_{0.4} \mathrm{Mn}_{0.4} \mathrm{Co}_{0.2} \mathrm{O}_{2} \\
\text { spherical particles }\end{array}$ & $\begin{array}{l}228 \mathrm{mAh} \mathrm{g}^{-1} \\
(0.05 \mathrm{C})\end{array}$ & & $\begin{array}{l}0.2 \% \text { decrease per cycle } \\
(20 \text { cycles })\end{array}$ & [6] \\
\hline $\mathrm{V}_{2} \mathrm{O}_{5}$ nanoparticles & $\begin{array}{l}285 \mathrm{mAh} \mathrm{g}^{-1} \\
(0.5 \mathrm{C})\end{array}$ & $\begin{array}{l}62.4 \% \text { retention } \\
(40 \text { times })\end{array}$ & $\begin{array}{l}0.44 \% \text { decrease per cycle } \\
(50 \text { cycles })\end{array}$ & [7] \\
\hline $\mathrm{V}_{2} \mathrm{O}_{5} /$ graphene & $\begin{array}{l}432 \mathrm{mAh} \mathrm{g}^{-1} \\
(0.05 \mathrm{C})\end{array}$ & $\begin{array}{l}45.8 \% \text { retention } \\
\text { (200 times) }\end{array}$ & $\begin{array}{l}0.13 \% \text { decrease per cycle } \\
(200 \text { cycles at } 1 \mathrm{C})\end{array}$ & {$[8]$} \\
\hline $\begin{array}{l}\mathrm{Li}_{4} \mathrm{Mn}_{2} \mathrm{O}_{5} \\
\text { composition }\end{array}$ & $\begin{array}{l}355 \mathrm{mAh} \mathrm{g}^{-1} \\
(0.05 \mathrm{C})\end{array}$ & & $\begin{array}{l}3.7 \% \text { decrease per cycle } \\
(8 \text { cycles })\end{array}$ & [9] \\
\hline $\begin{array}{l}\text { Hydrogenated } \mathrm{V}_{2} \mathrm{O}_{5} \\
\text { nanosheets }\end{array}$ & $\begin{array}{l}252 \mathrm{mAh} \mathrm{g}^{-1} \\
\left(0.1 \mathrm{~A} \mathrm{~g}^{-1}\right)\end{array}$ & $\begin{array}{l}54.8 \% \text { retention } \\
(20 \text { times })\end{array}$ & $\begin{array}{l}0.42 \% \text { decrease per cycle } \\
\left(200 \text { cycles at } 0.1 \mathrm{~A} \mathrm{~g}^{-1}\right)\end{array}$ & {$[10]$} \\
\hline
\end{tabular}

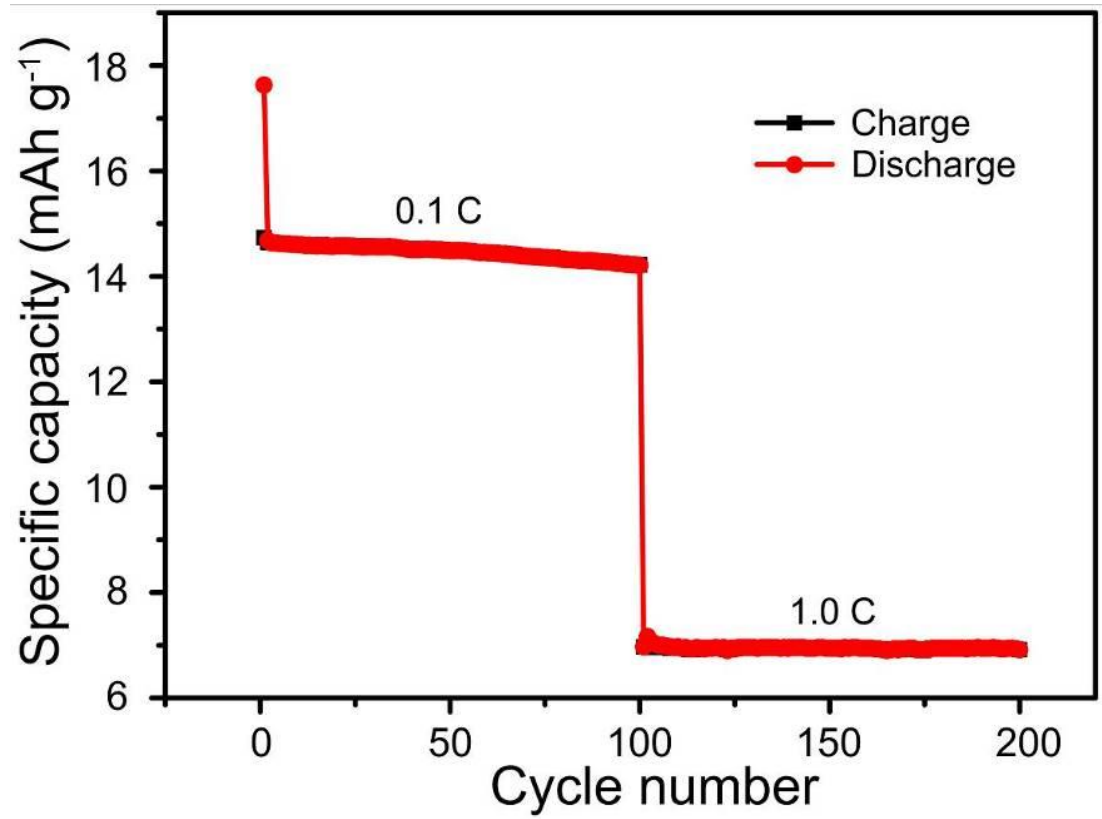

Figure S6. Rate capability of carbon clothes supported $\mathrm{NiCo}_{2} \mathrm{O}_{4}$ nanosheet arrays. 


\section{WILEY-VCH}

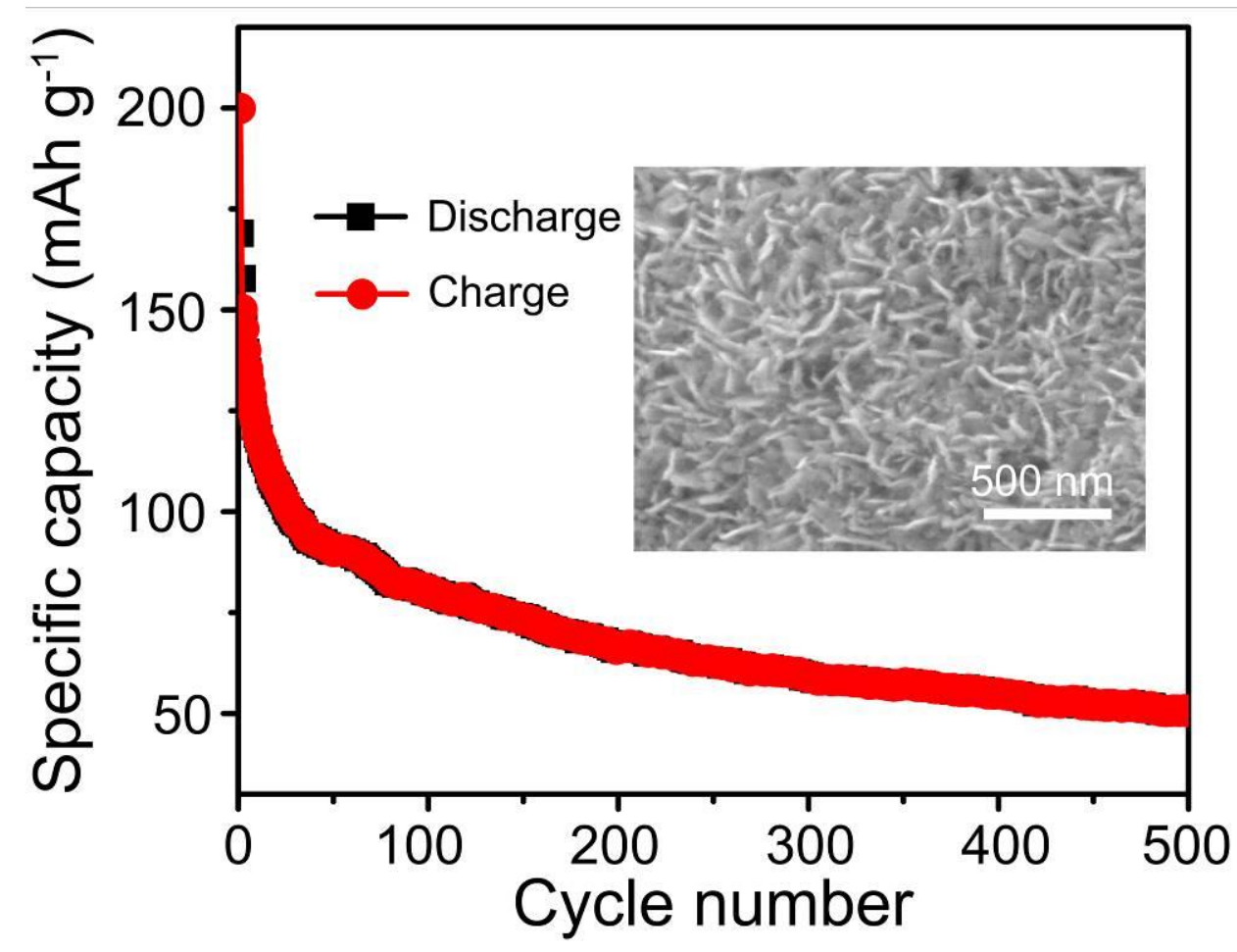

Figure S7. Cycling stability test of the $\mathrm{V}_{2} \mathrm{O}_{5}$ nanoflowers on carbon cloth at high current density of $10 \mathrm{C}$, inset showing the SEM image of the $\mathrm{V}_{2} \mathrm{O}_{5}$ nanoflowers on carbon clothes.

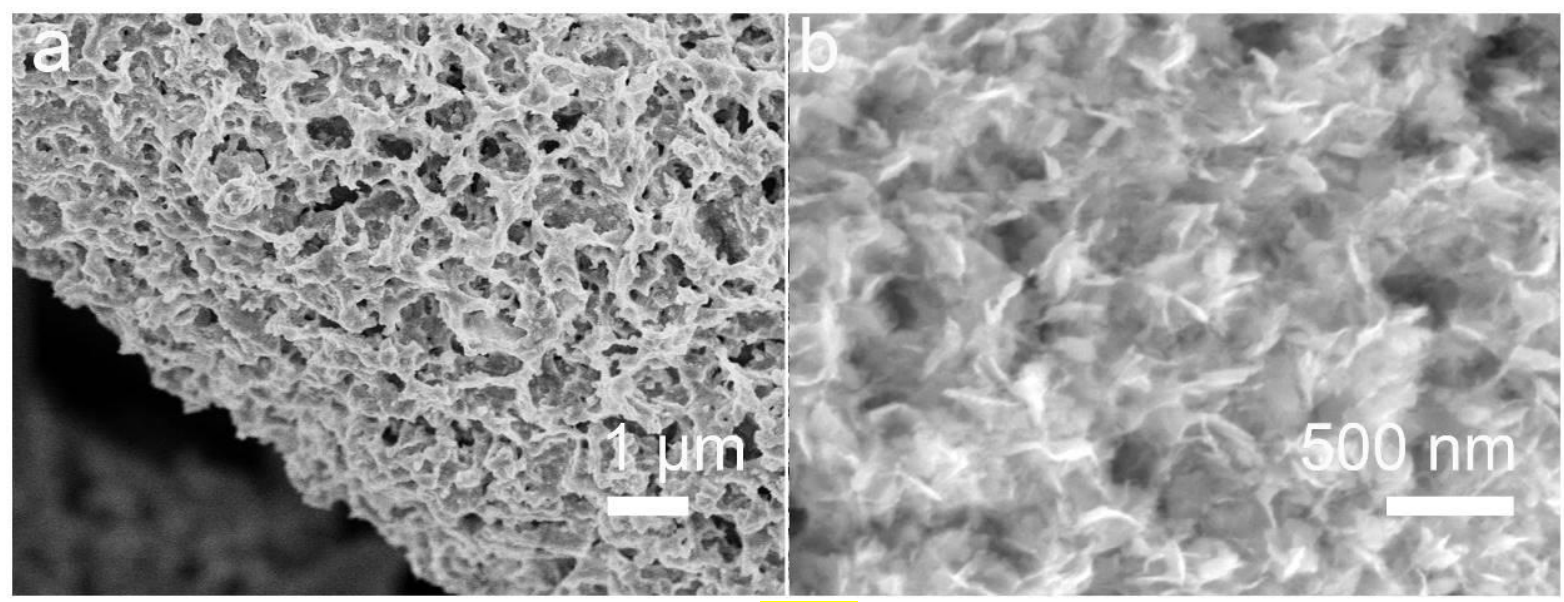

Figure S8. SEM images of $\mathrm{NiCo}_{2} \mathrm{O}_{4} @ \mathrm{~V}_{2} \mathrm{O}_{5}$ CSAs/carbon cloth and $\mathrm{V}_{2} \mathrm{O}_{5}$ nanoparticles after 500 cycles at the high current density of $10 \mathrm{C}$. 


\section{WILEY-VCH}

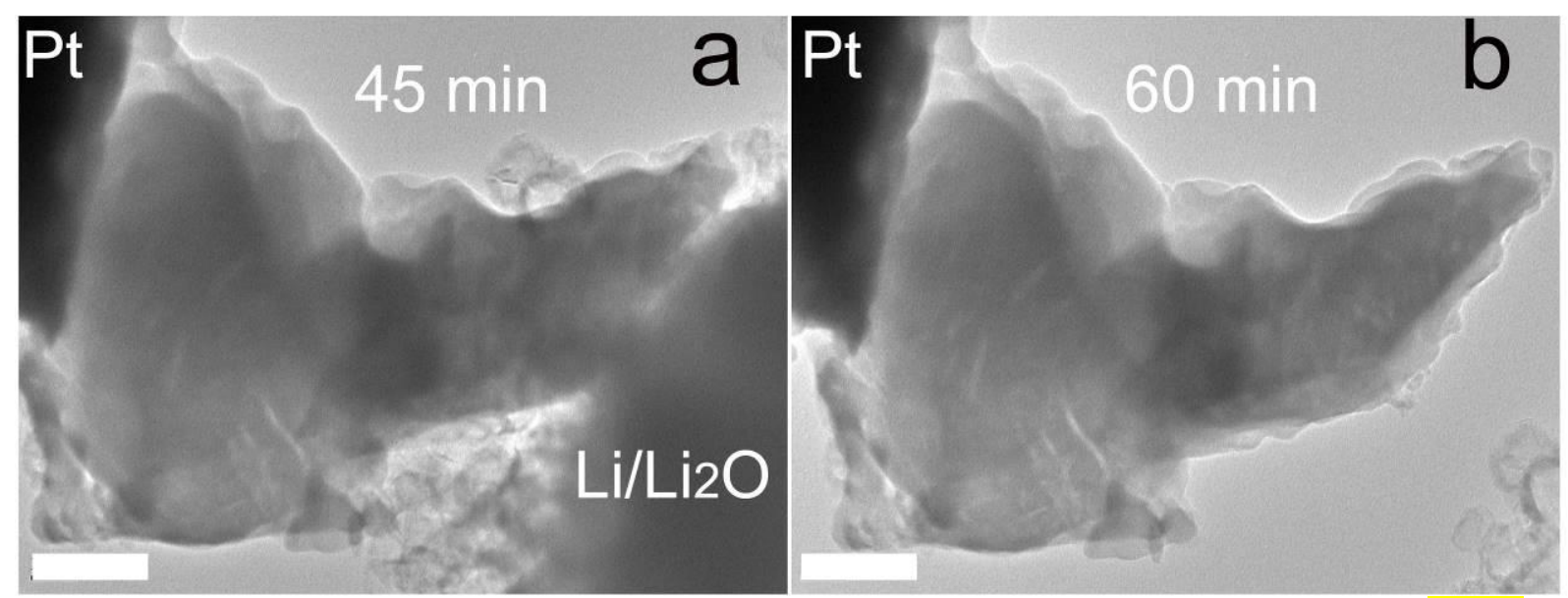

Figure S9. TEM images monitoring the de-lithiation process of the $\mathrm{NiCo}_{2} \mathrm{O}_{4} @ \mathrm{~V}_{2} \mathrm{O}_{5} \mathrm{CSAs}$ at time equal to 45 and $60 \mathrm{~min}$, respectively (Scale bar: $500 \mathrm{~nm}$ ).

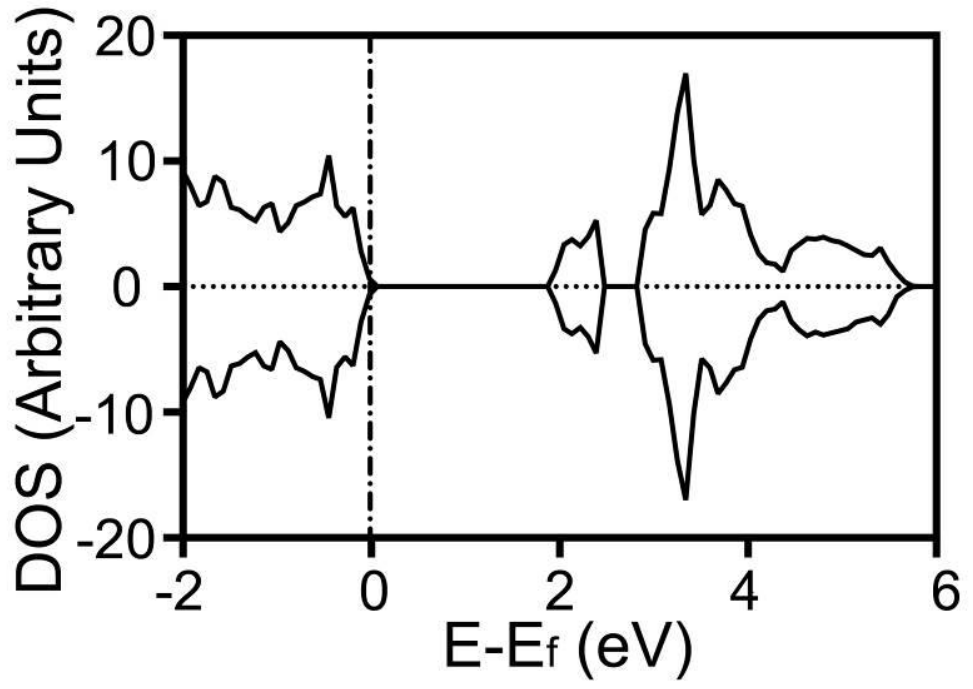

Figure S10. Calculated electronic density of states (DOS) and band structure of $\alpha-\mathrm{V}_{2} \mathrm{O}_{5}$. 


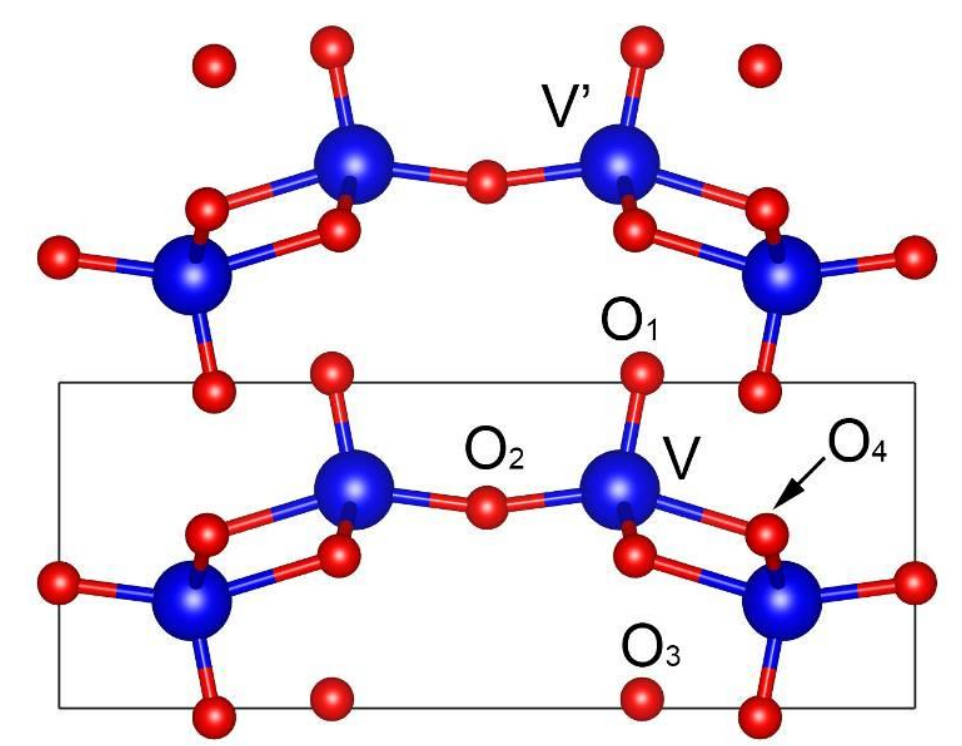

Figure S11. Side-view of two-layer $\alpha-\mathrm{V}_{2} \mathrm{O}_{5}$ structure, where the V-O bonds denoted.

Table S2. Comparison of different functional and van der Waals correction of lattice parameters and $\mathrm{V}-\mathrm{O}$ bond distances of bulk $\alpha-\mathrm{V}_{2} \mathrm{O}_{5}$ (Figure S10), as well as other simulation results and experimental data. The theoretical error is calculated based on experimental work.

\begin{tabular}{|c|c|c|c|c|c|c|c|c|}
\hline & $\mathbf{a}$ & $\mathbf{b}$ & c & $\mathrm{V}-\mathrm{O}_{1}$ & $\mathrm{~V}-\mathrm{O}_{2}$ & $\mathrm{~V}-\mathrm{O}_{3}$ & $\mathrm{~V}-\mathrm{O}_{4}$ & $V^{\prime}-O_{1}$ \\
\hline \multicolumn{9}{|c|}{ This work } \\
\hline PBEsol-vdW-DF & 11.567 & 3.581 & 4.392 & 1.606 & 1.793 & 1.884 & 2.036 & 2.786 \\
\hline error & $0.47 \%$ & $0.48 \%$ & $0.55 \%$ & $1.58 \%$ & $0.73 \%$ & $0.16 \%$ & $0.69 \%$ & $-0.25 \%$ \\
\hline PBE- vdW-DF2 & 11.833 & 3.663 & 4.493 & 1.624 & 1.824 & 1.927 & 2.091 & 2.870 \\
\hline optPBE-vdW & 11.648 & 3.606 & 4.422 & 1.609 & 1.802 & 1.897 & 2.048 & 2.814 \\
\hline \multicolumn{9}{|c|}{ Comparison } \\
\hline $\begin{array}{l}\text { Theoretical } \\
\text { work }^{[11]}\end{array}$ & 11.690 & 3.628 & 4.423 & 1.620 & 1.810 & 1.912 & 2.046 & 2.804 \\
\hline error & $1.55 \%$ & $1.80 \%$ & $1.26 \%$ & $2.47 \%$ & $1.69 \%$ & $1.65 \%$ & $1.19 \%$ & $0.39 \%$ \\
\hline $\begin{array}{l}\text { Theoretical } \\
\text { work }^{[12]}\end{array}$ & 11.496 & 3.630 & 4.804 & 1.602 & 1.805 & 1.915 & 2.018 & 3.204 \\
\hline error & $-0.14 \%$ & $1.85 \%$ & $9.98 \%$ & $1.33 \%$ & $1.40 \%$ & $1.81 \%$ & $-0.20 \%$ & $14.7 \%$ \\
\hline $\begin{array}{l}\text { Experimental } \\
\text { work }^{[13]}\end{array}$ & 11.512 & 3.564 & 4.368 & 1.581 & 1.780 & 1.881 & 2.022 & 2.793 \\
\hline
\end{tabular}




\section{WILEY-VCH}

Table S3. The binding energy (eV) of 1-5 layer $\alpha-\mathrm{V}_{2} \mathrm{O}_{5}$ at $\mathrm{nH}_{\mathrm{a}}, \mathrm{nH}_{\mathrm{b}}$ and $\mathrm{nT}$ sites, where $\mathrm{n}$ represent the layers. The $\mathrm{H}_{\mathrm{a}}, \mathrm{H}_{\mathrm{b}}$, and T sites are shown in Figure $5 \mathrm{c}$ and $\mathrm{d}$.

\begin{tabular}{|l|l|l|l|l|l|}
\hline & 1-Layer & 2 -Layer & 3-Layer & 4-Layer & 5-Layer \\
\hline $1 \mathrm{H}_{\mathrm{a}}$ & -2.76 & -2.81 & -2.81 & -2.81 & -2.80 \\
\hline $1 \mathrm{H}_{\mathrm{b}}$ & -1.40 & -1.47 & -1.45 & -1.45 & -1.35 \\
\hline $1 \mathrm{~T}$ & -2.41 & -2.44 & -2.42 & -2.28 & -2.80 \\
\hline $2 \mathrm{H}_{\mathrm{a}}$ & & -2.69 & -2.71 & -2.69 & -2.70 \\
\hline $2 \mathrm{H}_{\mathrm{b}}$ & & -1.59 & -1.66 & -1.64 & -1.65 \\
\hline $2 \mathrm{~T}$ & & -2.53 & -2.66 & -2.67 & -2.66 \\
\hline $3 \mathrm{H}_{\mathrm{a}}$ & & & -2.74 & -2.74 & -2.76 \\
\hline $3 \mathrm{H}_{\mathrm{b}}$ & & & -1.59 & -1.66 & -1.60 \\
\hline $3 \mathrm{~T}$ & & & -2.37 & -2.58 & -2.58 \\
\hline $4 \mathrm{H}_{\mathrm{a}}$ & & & & -2.73 & -2.74 \\
\hline $4 \mathrm{H}_{\mathrm{b}}$ & & & & -1.60 & -1.62 \\
\hline $4 \mathrm{~T}$ & & & & -2.36 & -2.36 \\
\hline $5 \mathrm{H}_{\mathrm{a}}$ & & & & & -2.74 \\
\hline $5 \mathrm{H}_{\mathrm{b}}$ & & & & & \\
\hline $5 \mathrm{~T}$ & & & & & -1.60 \\
\hline
\end{tabular}

Table S4. Simulated values of the Li diffusivity within layered $\alpha-\mathrm{V}_{2} \mathrm{O}_{5}$.

\begin{tabular}{|c|c|c|}
\hline Atom layers of $\mathrm{V}_{2} \mathrm{O}_{5}$ & $\begin{array}{c}\text { Inter-plane pathway } \\
\left(\mathrm{cm}^{2} \mathrm{~s}^{-1}\right)\end{array}$ & $\begin{array}{c}\text { In-plane pathway } \\
\left(\mathrm{cm}^{2} \mathrm{~s}^{-1}\right)\end{array}$ \\
\hline 1 & $1.53 \times 10^{-19}$ & $2.03 \times 10^{-11}$ \\
\hline 2 & $8.80 \times 10^{-21}$ & $5.26 \times 10^{-10}$ \\
\hline 3 & $2.49 \times 10^{-21}$ & $5.53 \times 10^{-9}$ \\
\hline 4 & $1.15 \times 10^{-21}$ & $7.31 \times 10^{-9}$ \\
\hline 5 & $5.34 \times 10^{-22}$ & $1.49 \times 10^{-7}$ \\
\hline
\end{tabular}




\section{WILEY-VCH}
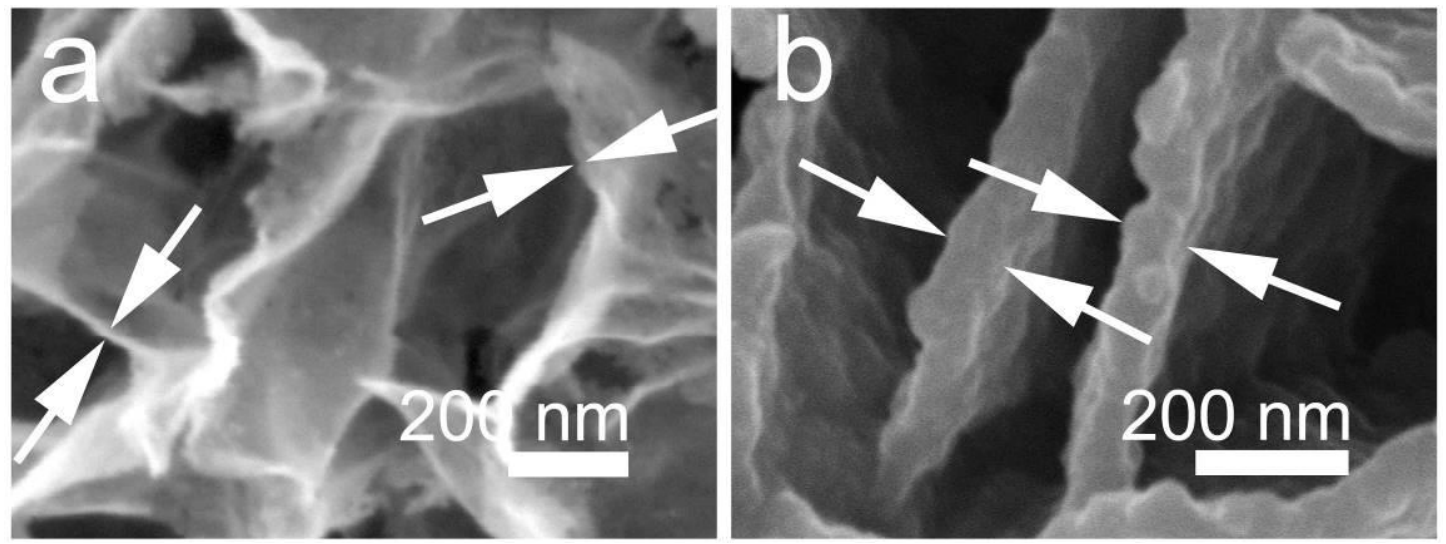

Figure S12. High magnification SEM of (a) $3 \mathrm{D} \mathrm{NiCo}_{2} \mathrm{O}_{4}$ nanosheets on carbon cloth; (b) $\mathrm{NiCo}_{2} \mathrm{O}_{4} @ \mathrm{~V}_{2} \mathrm{O}_{5} \mathrm{CSAs} /$ carbon cloth.

From the SEM images:

The average thickness of the $\mathrm{NiCo}_{2} \mathrm{O}_{4}$ nanosheets is $c a .21 .1 \mathrm{~nm}$

The average thickness of the $\mathrm{NiCo}_{2} \mathrm{O}_{4} @ \mathrm{~V}_{2} \mathrm{O}_{5}$ CSAs is $c a .86 .3 \mathrm{~nm}$
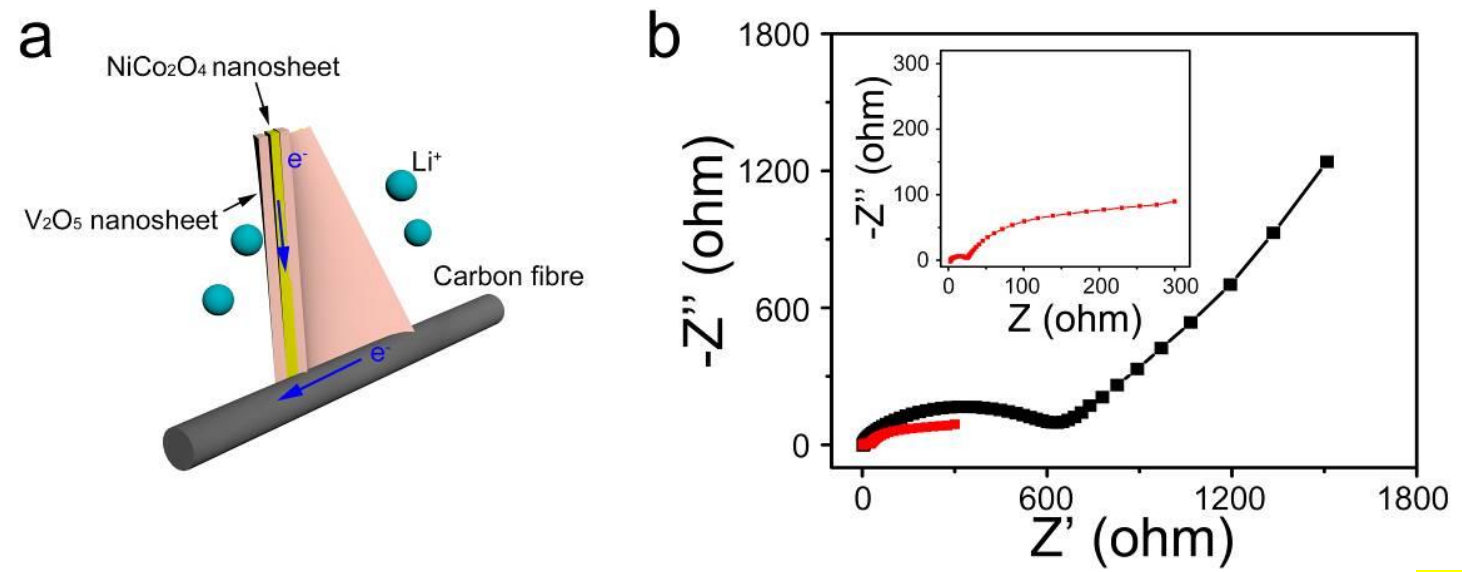

Figure S13. (a) Schematic illustration of electrochemical reactions of $\mathrm{NiCo}_{2} \mathrm{O}_{4} @ \mathrm{~V}_{2} \mathrm{O}_{5} \mathrm{CSAs}$; (b) EIS spectra of $\mathrm{NiCo}_{2} \mathrm{O}_{4} @ \mathrm{~V}_{2} \mathrm{O}_{5} \mathrm{CSAs} /$ carbon cloth (red line) and $\mathrm{V}_{2} \mathrm{O}_{5}$ nanoparticles (black line).

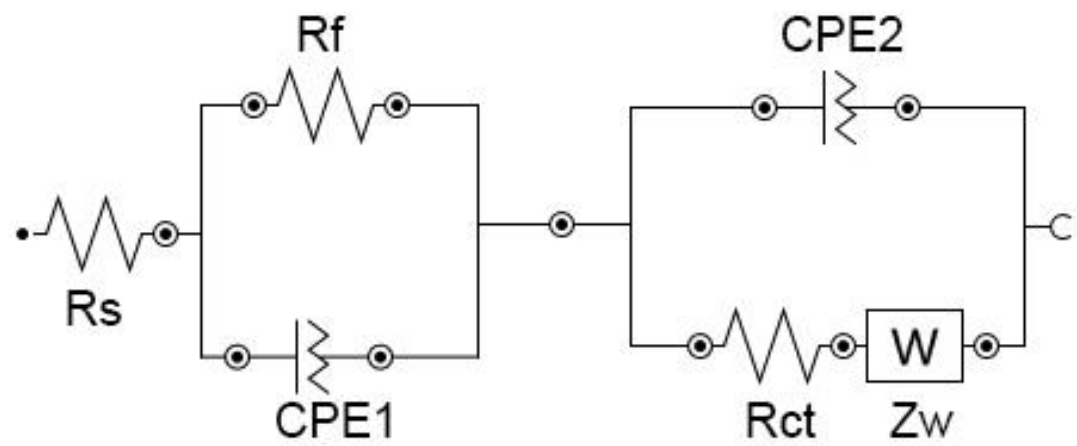

Figure S14. Equivalent circuit model of $\mathrm{NiCo}_{2} \mathrm{O}_{4} @ \mathrm{~V}_{2} \mathrm{O}_{5} \mathrm{CSAs} /$ carbon cloth and $\mathrm{V}_{2} \mathrm{O}_{5}$ nanostructure electrodes.

In the above equivalent circuit model, Rs is the electrolyte resistance; CPE1 and Rf are the capacitance and resistance of the passivation SEI film formed on the electrode surfaces, 
respectively; CPE2 and Rct are the double-layer capacitance and charge transfer resistance, respectively; and $\mathrm{Zw}$ is the Warburg impedance in regard to the diffusion of $\mathrm{Li}$ into the bulk of the electrode.

Table S5. Parameters from the equivalent circuit model.

\begin{tabular}{|c|c|c|}
\hline $\begin{array}{c}\text { Electrodes } \\
\text { Parameters }\end{array}$ & $\begin{array}{c}\mathrm{NiCo}_{2} \mathrm{O}_{4} @ \mathrm{~V}_{2} \mathrm{O}_{5} \\
\text { SAs/carbon cloth }\end{array}$ & $\mathrm{V}_{2} \mathrm{O}_{5}$ nanoparticles \\
\hline $\mathrm{R}_{\mathrm{f}}(\Omega)$ & 21.3 & 104 \\
\hline $\mathrm{R}_{\mathrm{ct}}(\Omega)$ & 223 & 454 \\
\hline $\mathrm{R}_{\mathrm{s}}(\Omega)$ & 2.87 & 3.14 \\
\hline
\end{tabular}

\section{Experimental Section}

Sample Preparation. All chemicals used in this work are commercially available from Sigma-Aldrich (UK) and were used as-received without further purification. The $\mathrm{NiCo}_{2} \mathrm{O}_{4} @ \mathrm{~V}_{2} \mathrm{O}_{5}$ CSAs were synthesized on carbon cloth using a two-step hydrothermal reaction combined with annealing. Firstly, $\mathrm{Co}\left(\mathrm{NO}_{3}\right)_{2} \bullet 6 \mathrm{H}_{2} \mathrm{O}(0.58 \mathrm{~g}), \mathrm{Ni}\left(\mathrm{NO}_{3}\right)_{2} \bullet 6 \mathrm{H}_{2} \mathrm{O}(0.29 \mathrm{~g})$ and methenamine $(0.56 \mathrm{~g})$ were dissolved into a solution of methanol $(35 \mathrm{~mL})$ to form a clear pink solution. The carbon cloth substrates were cleaned by sonication in acetone, deionized (DI) water and ethanol for 30 min sequentially, and then transferred into the autoclave with the above pink solution in an electrical oven at $160{ }^{\circ} \mathrm{C}$ for $6 \mathrm{~h}$. After the reaction, the NiCohydrate on carbon cloth was annealed at $300{ }^{\circ} \mathrm{C}$ for $2 \mathrm{~h}$ under air in the tube furnace. Four pieces of carbon cloth were prepared in the first step. Secondly, different amounts of vanadium oxytriisopropoxide $(0.1 \mathrm{ml}, 0.2 \mathrm{ml}, 0.4 \mathrm{ml}$ and $0.6 \mathrm{ml})$ were added into isopropanol alcohol $(50 \mathrm{~mL})$ in four separate beakers under vigorous stirring for $30 \mathrm{~min}$. The mixture solution was transferred into four $60 \mathrm{~mL}$ teflon-lined autoclaves with one piece of $\mathrm{NiCo}_{2} \mathrm{O}_{4}$ nanosheet arrays coated carbon cloth, which was sealed and heated in an electrical oven at $200{ }^{\circ} \mathrm{C}$ for $12 \mathrm{~h}$. Then, the as-synthesized materials on carbon clothes were washed with DI water and ethanol to remove any loosely attached powders and remove any residual ionic species and dried in a vacuum oven at $60{ }^{\circ} \mathrm{C}$ for $24 \mathrm{~h}$. At last, the as-synthesized samples on carbon clothes were annealed at $350{ }^{\circ} \mathrm{C}$ for $2 \mathrm{~h}$ under air in the tube furnace. 


\section{WILEY-VCH}

Characterization. Morphology and microstructure of the as-synthesized samples were characterized by SEM (S-4800; Hitachi) and TEM (JEOL, JEM-2100F equipped with an energy-dispersive X-ray spectrometer). X-ray diffraction patterns were recorded using a STOE StadiP diffractometer with Mo-Ka radiation $(\lambda=0.71 \AA)$. The surface chemical structures were evaluated using an X-ray photoelectron spectroscopy (XPS; Thermo scientific $\mathrm{K}$-alpha photoelectron spectrometer). The mass of the active materials was weighed using the accurate balance (readability of $0.001 \mathrm{mg}$ ). In-situ TEM observation of the lithiation process was performed using a scanning tunneling microscopy-TEM holder from Nanofactory Instruments AB (Gothenburg, Sweden) within the JEOL 2100F TEM, which was operated at $200 \mathrm{kV}$.

Electrochemical measurements. The $\mathrm{NiCo}_{2} \mathrm{O}_{4} @ \mathrm{~V}_{2} \mathrm{O}_{5} \mathrm{CSAs} /$ carbon cloth nanocomposites were used as working electrodes directly without adding any conductive agents or binder materials. The loading densities were calculated as 1.790-1.816, 2.594-2.618, 3.040-3.072, $3.640-3.812 \mathrm{mg} / \mathrm{cm}^{2}$ for the four kinds of samples, the $\mathrm{NiCo}_{2} \mathrm{O}_{4}$ nanosheet arrays was $0.994-$ $1.024 \mathrm{mg} / \mathrm{cm}^{2}$ on the carbon clothes. The $\mathrm{V}_{2} \mathrm{O}_{5} /$ carbon clothes is loaded with $\sim 1.76 \mathrm{mg} / \mathrm{cm}^{2}$ of $\mathrm{V}_{2} \mathrm{O}_{5}$. The mass of the carbon cloth in each coin cell is $\sim 18 \mathrm{mg}$. With regards to the comparison electrodes preparation, the working electrode was prepared by mixing the $\mathrm{V}_{2} \mathrm{O}_{5}$ nano-flowers (SEM image, Figure. S4a and XRD patterns, Figure. S4b), conductive agent (carbon black) and binder (sodium alginate) with a weight ratio of 50:40:10. Coin-type cells (CR2032) were fabricated using lithium metal as the counter electrode, Celgard 2400 (Charlotte, NC, USA) as the separator and $200 \mu \mathrm{L}$ of $50 \mathrm{LiPF}_{6}(1 \mathrm{M})$ in ethylene carbonatedimethyl carbonate $(1: 1 \mathrm{vol} \%)$ as the electrolyte. Cyclic voltammetry (CV) measurements were conducted at $0.1 \mathrm{mV} \mathrm{s}^{-1}$ in the range of $2.0 \sim 4.0 \mathrm{~V}\left(\right.$ vs. $\left.\mathrm{Li} / \mathrm{Li}^{+}\right)$on a $\mathrm{CHI} 600 \mathrm{D}$ 


\section{WILEY-VCH}

(Shanghai, China) electrochemical workstation. Electrochemical impedance spectroscopy was carried out with a ZAHNERelektrik IM 6 (Kronach) electrochemical system at a frequency range of $100 \mathrm{kHz}$ to $0.01 \mathrm{~Hz}$. All the electrochemical measurements were tested more than twice to ensure the replication of the results.

Theoretical methods of layer effect on lithiation in $\mathrm{V}_{2} \mathrm{O}_{5}$. DFT+U calculations were performed using a projector-augment wave (PAW) pseudopotential, implanted in the Vienna Ab initio Simulation Package(VASP). ${ }^{[14]}$ As the van der Waals interaction dominant the intralayer of $\alpha-\mathrm{V}_{2} \mathrm{O}_{5}$, serial functions have been adopted for comparison, including PBEsol-vdWDF, PBE-vdW-DF2, and optPBE-vdW..$^{[12,15-21]}$ The plane-wave basis set with energy cut-off of $520 \mathrm{eV}$. The Brillouin zone was sampled by Gamma centred $2 \times 2 \times 2 \mathrm{k}$-mesh for the bulk and $2 \times 2 \times 1$ for the layered slides. All structures were fully relaxed until the force on each atom was less than $0.01 \mathrm{eV}^{-1}$. Spin polarization counted through all the simulations. Due to the limitation of DFT calculations in presenting the delocalised $d$ and $f$ electrons excessively, ${ }^{[22]}$ the effective Coulomb and exchange parameters $+\mathrm{U}$ was set to $4 \mathrm{eV}$ as suggested in previous theoretical calculations. ${ }^{[23]}$

The $2 \mathrm{a} \times 2 \mathrm{~b}$ supercell of 1- to 5-layer $\alpha-\mathrm{V}_{2} \mathrm{O}_{5}$ have adopted for the analysis of the layer effect on Li intra-plane and inter-plane diffusion process. Dipole correction has adopted through all the calculations. For the few-layer $\mathrm{V}_{2} \mathrm{O}_{5}$, each model has $15 \AA$ vacuum region. Energy barrier of the Li were calculated by Climbing Image Nudged Elastic Band (Ci-NEB) method. $^{[24]}$

\section{References}

[1] X. Rui, Y. Tang, O. I. Malyi, A. Gusak, Y. Zhang, Z. Niu, H. T. Tan, C. Persson, X. Chen, Z. Chen, Q. Yan, Nano Energy 2016, 22, 583-593.

[2] D. Kong, X. Li, Y. Zhang, X. Hai, B. Wang, X. Qiu, Q. Song, Q.-H. Yang, L. Zhi, Energy Environ. Sci. 2016, $9,906-911$. 


\section{WILEY-VCH}

[3] S. Wang, Z. Lu, D. Wang, C. Li, C. Chen, Y. Yin, J. Mater. Chem. 2011, 21, 6365.

[4] H. Song, C. Liu, C. Zhang, G. Cao, Nano Energy 2016, 22, 1-10.

[5] H. Song, C. Zhang, Y. Liu, C. Liu, X. Nan, G. Cao, J. Power Sources 2015, 294, 1-7.

[6] F. Lin, D. Nordlund, Y. Li, M. K. Quan, L. Cheng, T.-C. Weng, Y. Liu, H. L. Xin, M. M. Doeff, Nature Energy 2016, 1, 15004.

[7] T. Kim, J. Shin, T.-S. You, H. Lee, J. Kim, Electrochim. Acta 2015, 164, 227-234.

[8] Q. Liu, Z. F. Li, Y. Liu, H. Zhang, Y. Ren, C. J. Sun, W. Lu, Y. Zhou, L. Stanciu, E. A. Stach, J. Xie, Nat. Commun. 2015, 6, 6127.

[9] M. Freire, N. V. Kosova, C. Jordy, D. Chateigner, O. I. Lebedev, A. Maignan, V. Pralong, Nat. Mater. 2016, 15, 173-177.

[10] X. Peng, X. Zhang, L. Wang, L. Hu, S. H.-S. Cheng, C. Huang, B. Gao, F. Ma, K. Huo, P. K. Chu, Adv. Funct. Mater. 2016, 26, 784-791.

[11] J. Carrasco, J. Phys. Chem. C 2014, 118, 19599-19607.

[12] D. O. Scanlon, A. Walsh, B. J. Morgan, G. W. Watson, J. Phys. Chem. C 2008, 112, 9903-9911.

[13] R. Enjalbert, J. A. Galy, Acta Crystallogr. C 1986, C42, 1467-1469.

[14] G. Kresse, J. Furthmuller, Phys. Rev. B 1996, 54, 169-186.

[15] J. P. Perdew, J. A. Chevary, S. H. Vosko, K. A. Jackson, M. R. Pederson, D. J. Singh, C. Fiolhais, Phys. Rev. B 1992, 46, 6671-6687.

[16] K. Lee, É. D. Murray, L. Kong, B. I. Lundqvist, D. C. Langreth, Phys. Rev. B 2010, 82, 081101(R).

[17] T. Thonhauser, V. R. Cooper, S. Li, A. Puzder, P. Hyldgaard, D. C. Langreth, Phys. Rev. B 2007, 76, 125112.

[18] M. Dion, H. Rydberg, E. Schroder, D. C. Langreth, B. I. Lundqvist, Phys. Rev. Lett. 2004, 92, 246401.

[19] J. Klimes, D. R. Bowler, A. Michaelides, J. Phys. Condens. Matter. 2010, 22, 022201.

[20] J. Klimeš, D. R. Bowler, A. Michaelides, Phys. Rev. B 2011, 83, 195131.

[21] G. Roman-Perez, J. M. Soler, Phys. Rev. Lett. 2009, 103, 096102.

[22] S. Fabris, S. de Gironcoli, S. Baroni, G. Vicario, G. Balducci, Phys. Rev. B 2005, 72, 041102(R).

[23] G. Henkelman, B. P. Uberuaga, H. Jónsson, J. Phys. Chem. 2000, 113, 9901.

[24] J. P. Perdew, A. Ruzsinszky, G. I. Csonka, O. A. Vydrov, G. E. Scuseria, L. A. Constantin, X. Zhou, K. Burke, Phys. Rev. Lett. 2008, 100, 136406. 